\title{
Epiphyte response to drought and experimental warming
}

\section{[version 1; peer review: 1 approved, 1 approved with}

\section{reservations]}

\author{
Joshua M. Rapp ${ }^{1,2}$, Miles R. Silman ${ }^{1}$ \\ ${ }^{1}$ Department of Biology, Wake Forest University, Winston Salem, NC, 27109, USA \\ ${ }^{2}$ Current address: Department of Biology, Tufts University, Medford, MA, 02155, USA
}

V1 First published: 13 Jan 2014, 3:7

https://doi.org/10.12688/f1000research.3-7.v1

Latest published: 06 Jun 2014, 3:7

https://doi.org/10.12688/f1000research.3-7.v2

\section{Abstract}

The high diversity and abundance of vascular epiphytes in tropical montane cloud forest is associated with frequent cloud immersion, which is thought to protect plants from drought stress. Increasing temperature and rising cloud bases associated with climate change may increase epiphyte drought stress, leading to species and biomass loss. We tested the hypothesis that warmer and drier conditions associated with a lifting cloud base will lead to increased mortality and/or decreased recruitment of epiphyte ramets, altering species composition in epiphyte mats. By using a reciprocal transplant design, where epiphyte mats were transplanted across an altitudinal gradient of increasing cloud immersion, we differentiated between the effects of warmer and drier conditions from the more general prediction of niche theory that transplanting epiphytes in any direction away from their home elevation should result in reduced performance. Ramet mortality increased, recruitment decreased, and population size declined for epiphytes in mats transplanted down slope from the highest elevation, into warmer and drier conditions, but epiphytes from lower elevations showed greater resistance to drought in all treatments. Epiphyte community composition changed with elevation, but over the timescale of the experiment there were no consistent changes in species composition. Our results suggest some epiphytes may show resistance to climate change depending on the environmental context, although if climate change results in consistently drier conditions and higher cloud bases, biomass loss and shifting species composition in epiphyte communities is likely.

\section{Keywords}

Andes, cloud immersion, reciprocal transplant, cloud base, altitudinal gradient

\section{Open Peer Review \\ Approval Status \\ $\checkmark$ \\ 1 \\ 2 \\ version 2 \\ (revision) \\ 06 Jun 2014 \\ version 1 \\ $13 \operatorname{Jan} 2014$

........................... \\ 1. Peter Hietz, University of Natural Resources and Applied Life Sciences, Vienna, Austria
2. Liang Song, Chinese Academy of Sciences, Kunming, China

Any reports and responses or comments on the article can be found at the end of the article. 


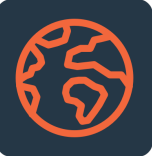

This article is included in the Climate gateway.

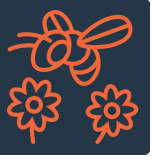

This article is included in the Ecology and

Global Change gateway.

Corresponding author: Joshua M. Rapp (rapp.joshua@gmail.com)

Competing interests: No competing interests were disclosed.

Grant information: Funding was generously provided by a Wake Forest University Biology Department Vecellio Fund grant to J.M. Rapp, and grants from the Gordon and Betty Moore Foundation Andes to Amazon Program, NSF EAR 0711414, NSF DEB-0237684, and an NSF REU supplement DEB-0237684 to M.R. Silman.

The funders had no role in study design, data collection and analysis, decision to publish, or preparation of the manuscript.

Copyright: ( 2014 Rapp JM and Silman MR. This is an open access article distributed under the terms of the Creative Commons Attribution License, which permits unrestricted use, distribution, and reproduction in any medium, provided the original work is properly cited. Data associated with the article are available under the terms of the Creative Commons Zero "No rights reserved" data waiver (CC0 1.0 Public domain dedication).

How to cite this article: Rapp JM and Silman MR. Epiphyte response to drought and experimental warming [version 1; peer review: 1 approved, 1 approved with reservations] F1000Research 2014, 3:7 https://doi.org/10.12688/f1000research.3-7.v1

First published: 13 Jan 2014, 3:7 https://doi.org/10.12688/f1000research.3-7.v1 


\section{Introduction}

Tropical montane forests, often referred to as cloud forests, harbor high species diversity, provide water and protect water quality for numerous people in tropical countries, and are under particular threat from climate change $\mathrm{e}^{1-3}$. Most cloud forest regions of the world, including the tropical Andes, are considered hotspots of biological diversity $^{4}$, and plant species endemism often reaches high levels within cloud forest ${ }^{5,6}$. Epiphytes, non-parasitic plants that depend on other plants for support and are not in contact with terrestrial soil, are key components of cloud forest biodiversity and play critical roles in the hydrological and nutrient cycling of montane ecosystems. Not only can vascular epiphytes make up 30 percent or more of plant species diversity in tropical montane forests ${ }^{7}$, they also provide keystone resources for birds, insects, and other animals ${ }^{8-11}$. Through cloud stripping, epiphytes increase total moisture captured by forest canopies $^{12-14}$, and are important in nutrient cycling ${ }^{15,16}$. Cloud immersion is important for many epiphyte species to maintain a positive water balance and avoid desiccation ${ }^{17}$. Because of their sensitivity to moisture levels, epiphytes are considered indicator species in cloud forests for changing water balance conditions ${ }^{18}$, particularly those in the wet tropics ${ }^{19}$.

On a typical tropical mountain, where temperature decreases with altitude, there is a gradient of increasing cloud incidence with altitude. Cloud formation is dependent on the vapor content of air and air temperature, both of which are predicted to change with global warming ${ }^{1}$. Atmospheric moisture levels are much less easily predicted than temperature in climate models, but a multi-model ensemble of climate simulations showed a trend towards drying in many tropical regions ${ }^{20}$. Climate model projections in the Andes include warmer temperatures and lower precipitation in the dry season $^{21-23}$, which could place cloud forest plants under increased drought stress. Cloud base height is also predicted to rise, due to a combination of higher temperature and lower atmospheric moisture input by vegetation due to lowland deforestation and reduced transpiration because of increased atmospheric $\mathrm{CO}_{2}{ }^{24-26}$. In Costa Rica, an increase in the elevation of cloud base has been demonstrated and has already lead to the extinction of cloud forest species ${ }^{27}$, although this may have been associated with a severe El Niño event in 1986-87 rather than a long term drying trend ${ }^{28}$.

The sensitivity of vascular epiphytes to changes in cloud incidence was demonstrated experimentally in Monteverde, Costa Rica, where vascular epiphytes transplanted below the cloud base had shorter lifespans and higher leaf mortality ${ }^{29}$. It is not clear, however, whether this result can be generalized to continental cloud forests such as the eastern Andes. Cloud forests vary worldwide, with differences in cloud base height and the proportion of moisture received by the vegetation via cloud stripping versus rainfall ${ }^{30,31}$. Cloud forests near coastlines are heavily influenced by ocean conditions ${ }^{32}$, while cloud formation on continental mountain ranges is dependent on moisture flux across continents driven by synoptic weather patterns. Deforested areas in Costa Rica have fewer clouds than adjacent forested areas $^{33}$, but simulations suggest that sea-surface temperature has a greater impact on lifting condensation level than deforestation $^{34}$. Cloud forests in continental mountains like the Andes are expected to be more sensitive to conditions of the adjoining lowland ecosystems, particularly deforestation ${ }^{25,32}$. In addition, complex topography in the eastern Andes and its interaction with prevailing winds leads to wet and dry areas within regions broadly considered cloud forest ${ }^{35}$. Given the diversity of cloudiness and precipitation regimes that epiphytes as a group are exposed to, it is reasonable to expect that epiphytes may be adapted to local moisture regimes. For instance, epiphytes in lowland dry or seasonal forest have high desiccation tolerance ${ }^{36,37}$. Epiphytes in continental cloud forests like the Andes, which experience variable cloudiness regimes, may have more resistance to drought than those in locations with more stable cloud bases. Likewise, epiphytes growing at lower elevations, below the cloud base, may have greater drought tolerance than epiphytes growing above the cloud base.

Beginning in the 2005 austral winter (June and July), we conducted a year-long reciprocal transplant experiment across an elevational gradient in cloud formation in the eastern Andes of southern Peru to test the effect that cloud immersion has on the performance of vascular epiphytes. The reciprocal transplant design also allowed us to distinguish between the effects of moving mats away from their home elevation versus moving plants into lower moisture conditions. This is a key control, not often made climate change transplant studies $\left[\right.$ e.g..$^{29,38}$, for if epiphytes are locally adapted, reduced performance is expected if moved in any direction from their bioclimatic optimum. The specific questions we addressed were: (1) Does demographic performance decline when epiphytes are moved farther from their home elevation? (2) Is this effect greater when transplanted down-slope into drier and warmer conditions as predicted by results from Costa Rica? ${ }^{29}$ (3) Do epiphyte species of different functional types (e.g. strap-leaf ferns, orchids, ericaceous shrubs) respond similarly to moisture gradients?

We focused on three aspects of demographic performance, ramet survival, recruitment, and change in population size. Ramet survival allows us to examine treatment effects on existing individuals, while ramet recruitment and population change gives insight into treatment effects on epiphyte populations. We expected that ramet survival and recruitment would decrease and population change become negative as mats were moved farther from their home elevation. We also hypothesized that the decrease in ramet survival and recruitment would be greater for mats moved down-slope than for mats moved upslope if moisture level is the dominant factor in determining epiphyte species distributions. A priori, we expected different functional types to respond similarly to the altitudinal gradient such that any transplant effect would be similar across groups. Specifically, we expected functional types to have differing ramet mortality, but that these would be balanced by ramet production such that species composition would remain stable in undisturbed mats.

\section{Materials and methods}

\section{Study area}

The Kosñipata Valley $\left(13^{\circ} 03^{\prime} \mathrm{S}, 71^{\circ} 33^{\prime} \mathrm{W}\right)$ lies along the eastern slope of the Andes in southern Peru. Elevations range from about $800 \mathrm{~m}$ to over $4000 \mathrm{~m}$, and vegetation changes from pre-montane rainforest at the lowest elevations to tropical subalpine forest and puna (alpine grassland) at the highest elevations ${ }^{39}$. The experiment was installed along a single forested ridge, with three transplant sites at 1500,1650 , and $1800 \mathrm{~m}$. We chose these elevations because 
the large increase in vascular epiphyte and bryophyte biomass ${ }^{40}$, and step changes in soil properties ${ }^{41}$ and biomass carbon stocks ${ }^{42}$ between 1500 and $2000 \mathrm{~m}$ elevation in the Kosñipata Valley are likely associated with higher cloud incidence and lower temperatures, as seen on other tropical mountains ${ }^{43,44}$. The bedrock underlying the ridge is Permian granite, and soils are classified as umbric Gleysols $^{45}$.

The Kosñipata Valley has a perhumid climate described in detail in Rapp and Silman ${ }^{46}$. Temperature decreases linearly with altitude and annual rainfall is high across the gradient, with a distinct, but weak dry season (monthly rainfall $>$ monthly potential evapotranspiration except during drought). Vapor pressure deficit (VPD) typically decreases with altitude across the east Andean slope above $1500 \mathrm{~m}$ for all months except June ${ }^{46}$. While differences in VPD between $1500 \mathrm{~m}$ (lowest experimental elevation) and $1800 \mathrm{~m}$ (highest experimental elevation) are typically small, excursions to higher VPD (greater desiccation) are more severe at $1500 \mathrm{~m}^{46}$. The dry season (May - August) is when cloud immersion is expected to be most important for cloud forest plants. In July, the driest month, high relative humidity associated with cloud immersion (>95\%) is more common at $1840 \mathrm{~m}$ than at $1500 \mathrm{~m}$ at climate stations approximately $1 \mathrm{~km}$ from the study site, while vapor pressure deficits greater than $1.0 \mathrm{kPa}$ are more common at the higher elevation (Table 1). Vapor pressure deficits greater than $1.0 \mathrm{kPa}$ are associated with moisture stress in cloud forest plants ${ }^{47,48}$. Daily photographs during installation of the experiment in June and July 2005 and July 2006, confirmed that cloud base height did not differ between years $\left(\mathrm{X}^{2}=3.32, \mathrm{p}=0.19\right)$, and that cloud frequency increased with elevation (cloud base $<1500 \mathrm{~m}$ in $9 \%$ of observations; $1500-1800 \mathrm{~m}$ in $30 \%$ of observations; $>1800$ in $61 \%$ of observations).

\section{Data collection}

In the 2005 austral winter (dry season: June and July), we selected five Alzatea verticillata Ruiz \& Pav. trees at each of three elevations, 1500 meters, 1650 meters, and 1800 meters elevation. Alzatea was an appropriate choice for a host tree because: (1) it was common at all three elevations; (2) it attains large size and has strong wood suitable for supporting climbers working in the trees; and (3) its unique architecture resulted in many large horizontal branches that supported sizeable epiphyte mats. We accessed trees using roped arborist techniques ${ }^{49}$. In each tree, we chose four sections of epiphyte mat that were at least $25 \mathrm{~cm}$ wide and $30-40 \mathrm{~cm}$ long. Within each of the 60 mats, we marked an area of $25 \times 25 \mathrm{~cm}$ with wire, and marked all ramets of vascular epiphytes within it, identified them to morphospecies, and recorded the length of shoots and number of leaves of each ramet. Nonvascular epiphytes were present, but not considered in this experiment. Most mat dwelling epiphytes are clonal, with individual ramets connected by subsurface stems, but capable of surviving without connection to other ramets. It was difficult to determine individual genets without excavating the plants, so we identified and measured individual ramets rather than genetically distinct plants. For strap-leafed ferns in the genus Elaphoglossum, each ramet was a single leaf, while ramets for other species consisted of one or more stems with multiple leaves. On each tree, one of the mats was left in place to serve as an undisturbed control. We cut each of the other three mats from the tree, lowered them to the ground, and then transplanted one each to a random tree at each of the three elevations. After all transplants were complete, each tree had one undisturbed mat, one mat that had been removed and then replaced at the same elevation, and one mat from each of the other two elevations. We tied each mat in place using wire, and then watered it with one liter of water to minimize any desiccation effect that handling may have had. Supplementary Figure 1Supplementary Figure 4 illustrate the process of transplanting the epiphyte mats.

We left the mats undisturbed for one year, and resurveyed them the following year in June and July 2006 (Dataset). We searched for all marked ramets and counted the new ramets of each morphospecies. We assumed ramets obviously more than a year old ( 28 out of $1400+$ original ramets) had lost their tag if previously marked ramets of the same species were not found in the same mat. Eight 'old' ramets were still not accounted for; we assumed these were missed during the first census. Any other missing ramets were assumed to be dead.

Survey of epiphytes before and after transplantation across an altitudinal gradient of increasing cloud immersion along the eastern slope of the Andes, Peru

1 Data File

http://dx.doi.org/10.6084/m9.figshare.894979

Table 1. July climate for weather stations within 1 kilometer of the transplant sites. Values represent the mean for July in 2007, 2008, and 2009, except for precipitation, which does not include data for 2007 . $\mathrm{RH} 95$ is the proportion of time relative humidity was greater than $95 \%$. VPD excursions is the number of days per month in which vapor pressure deficit (VPD) was 1.0 $\mathrm{kPa}$ or greater.

\begin{tabular}{|llllll|}
$\begin{array}{l}\text { Elevation } \\
(\mathbf{m})\end{array}$ & $\begin{array}{l}\text { Temperature } \\
\left({ }^{\circ} \mathbf{C}\right)\end{array}$ & $\begin{array}{l}\text { Precipitation } \\
(\mathbf{m m} / \text { day) }\end{array}$ & $\begin{array}{l}\text { Relative humidity } \\
(\%)\end{array}$ & $\begin{array}{l}\text { RH9 5 } \\
(\%)\end{array}$ & $\begin{array}{l}\text { VPD } \\
\text { excursions } \\
\text { (days/month) }\end{array}$ \\
\hline 1500 & 17.2 & 7.5 & 88.3 & 0.27 & 1.7 \\
\hline 1840 & 16.1 & 4.6 & 88.4 & 0.32 & 0 \\
\hline
\end{tabular}


With these data, we defined three measures of population performance: 1) survival, 2) recruitment, and 3) population change. Survival was defined as:

Survival $=\left(\mathrm{N}_{2005}-\mathrm{D}_{2006}\right) / \mathrm{N}_{2005}$,

where $\mathrm{N}_{2005}$ was the number of ramets surveyed in a mat in 2005, and $\mathrm{D}_{2006}$ was the number of ramets surveyed in 2005 that had died by 2006 . Recruitment was defined as:

Recruitment $=\mathrm{n}_{2006} / \mathrm{N}_{2005}$,

where $\mathrm{n}_{2006}$ was the number of new ramets surveyed in 2006, which were not present in 2005. Population change was defined as:

Population change $=\left(\mathrm{N}_{2006}-\mathrm{N}_{2005}\right) / \mathrm{N}_{2005}$.

\section{Statistical analysis}

All analyses were performed using the mat as the experimental unit to account for within-mat correlations between ramets, i.e. to avoid pseudo replication. We fitted models to data that included all ramets irrespective of species to explore the overall community patterns of ramet survival, recruitment, and population change, and then modeled common species separately to look at individual species responses. The common species occurred in at least half (10) of all epiphyte mats transplanted from at least one elevation. These included four common morpho-species identified to genus, by which we will refer to them: a strap-leaf fern (Elaphoglossum Schott ex J. Sm.), two orchid species (Maxillaria Ruiz \& Pav.; Scaphyglottis Poepp. \& Endl), and an ericaceous shrub (Cavendishia Lindl.). Collectively, these species accounted for $78 \%$ (1127/1452) of the ramets surveyed in the initial 2005 survey (Table 2).

We tested whether ramet recruitment was different than mortality in transplanted mats using a two-sided t-test. We then analyzed ramet survival, recruitment, and population change with respect to experimental manipulations using generalized linear mixed-effects models (GLMMs). Survival was modeled as a binomial distribution with a logit link function to account for the binary nature of the response (alive, dead). Recruitment (new ramets in 2006) and population change (total ramets in 2006) were modeled as a rate relative to the initial ramets per mat by using a Poisson distribution with a $\log$ link, and adding an offset of the log of the number of initial ramets in 2005 . To account for the natural blocking by tree in our experimental design, models that included multiple source elevations and transplant elevations also included random effects for source tree and transplant tree. Models including only one source elevation included a random effect for source tree only. Likelihood ratio tests were used to assess the fixed effects, while Wald z-tests were used to evaluate differences between levels of fixed effects. We did not evaluate the significance of random effects because they were a required part of our experimental design. Finally, we confirmed that the residuals of the final model were not overdispersed ${ }^{50}$ using code from Bolker et al. ${ }^{51}$. All analyses were done in R [Version 2.15.2.52]. In all analyses we considered an effect significant if the $\mathrm{P}$-value was less than 0.05 .

First, we tested for an effect of manipulating mats using data for undisturbed control mats and mats transplanted within elevation. Source elevation and treatment (transplant versus undisturbed) were modeled as fixed effects in this analysis. Then, we tested for effects of source and transplant elevation on the response variable, using data from just the transplanted mats. We took this two-tiered approach because a full model including all mats was unbalanced (e.g. there could not be a control mat that moved between elevations) and statistical models accounting for this would not converge computationally.

To investigate patterns in mat species composition we used Detrended Correspondance Analysis (DCA) because our compositional data collected across a directional gradient matched the assumptions of DCA. First, we investigated the change in composition versus elevation using the pre-transplantation composition of all mats. We then investigated compositional change due to experimental treatments by ordinating the composition of all mats during 2005 before transplantation, with the composition of mats in 2006, one year after transplantation. Permutation Multivariate Analysis of Variance using distance matrices [function adonis in the vegan R package ${ }^{53}$ ] was used to test for compositional changes with altitude and among years due to the transplantation.

\section{Results}

Transplant effect: transplants within elevation

First, we tested for an effect of transplantation independent of elevational distance moved by asking whether epiphytes in mats transplanted to the same elevation had different ramet survival, recruitment, and population change or turn-over than those in intact mats. Across all species, there was no significant effect of transplant, elevation, or their interaction on survival, recruitment, or population

Table 2. Number of ramets in surveyed mats before transplanting. Numbers in parentheses indicate number of mats the ramets were found in. Bold indicates ramets used in single species analyses.

\begin{tabular}{|c|c|c|c|c|c|c|}
\hline \multicolumn{7}{|c|}{ Species } \\
\hline Elevation (m) & Elaphoglossum & Maxillaria & Cavendishia & Schaphyglottis & All other species & Total \\
\hline 1500 & 346 (19) & $16(3)$ & $11(4)$ & $0(0)$ & $181(12)$ & $554(20)$ \\
\hline 1650 & $163(19)$ & $118(17)$ & $46(11)$ & $33(8)$ & $55(10)$ & $415(20)$ \\
\hline 1800 & 197 (19) & $96(14)$ & $20(8)$ & $81(10)$ & $89(17)$ & $483(20)$ \\
\hline Total & $706(57)$ & $230(34)$ & $77(23)$ & $114(18)$ & 325 (39) & $1452(60)$ \\
\hline
\end{tabular}


change of epiphyte ramets (Table 3, Figure 1). However, individual species were affected by transplantation. For Elaphoglossum, survival was lower in mats transplanted to another site at the same elevation than in undisturbed controls, but there was no effect of elevation on survival or any interaction between elevation and transplantation (Table 4, Figure 1). There was an interaction between elevation and transplantation for recruitment and population change in Elaphoglossum, however (Table 4); both were lower for transplanted mats at $1500 \mathrm{~m}$ and $1650 \mathrm{~m}$, but higher for mats transplanted at $1800 \mathrm{~m}$ (Figure 1). For Maxillaria, recruitment was lower in transplanted mats, but not affected by elevation, and neither survival nor population change was affected by either transplanting or elevation (Table 4, Figure 1). For Cavendishia, recruitment and population change were lower for transplanted mats (Figure 1), but only significantly so for recruitment; survival was unaffected by transplantation (Table 4). Transplanting did not affect survival, recruitment, or population change in Schaphyglottis (Table 4, Figure 1).

Transplants across elevation

Across all species, there were no significant effects on survival of any of the treatments for mats transplanted across elevations (Table 5 and Figure 2). For recruitment and population change, there was a significant interaction between source and transplant elevation (Table 5), with both positively associated with elevation for mats transplanted from 1500 and $1800 \mathrm{~m}$, but negatively associated with altitude for mats from $1650 \mathrm{~m}$ (Figure 2). Overall for transplanted mats, more ramets died than were recruited (mean change number of ramets per mat between years $=-1.38$; two-sided t-test, $P=0.01$ ).

Elaphoglossum ramets in mats originating at $1500 \mathrm{~m}$ had consistently and significantly higher survival than those originating at $1650 \mathrm{~m}$ or $1800 \mathrm{~m}$, but there was no effect of transplant elevation on survival (Table 6, Figure 2). For both recruitment and population change, however, there was a significant interaction between source elevation and transplant elevation, with both recruitment and population change declining in mats transplanted at lower elevations for mats originating at $1500 \mathrm{~m}$ and $1800 \mathrm{~m}$, but for mats originating at $1650 \mathrm{~m}$ recruitment was greater and population change more positive for mats transplanted to $1500 \mathrm{~m}$ than for mats transplanted to higher elevation (Table 6, Figure 2).

For Maxillaria, the only significant effect for transplanted mats was that for transplant elevation on recruitment (Table 6); recruitment was low in all transplanted mats, but there was zero recruitment in
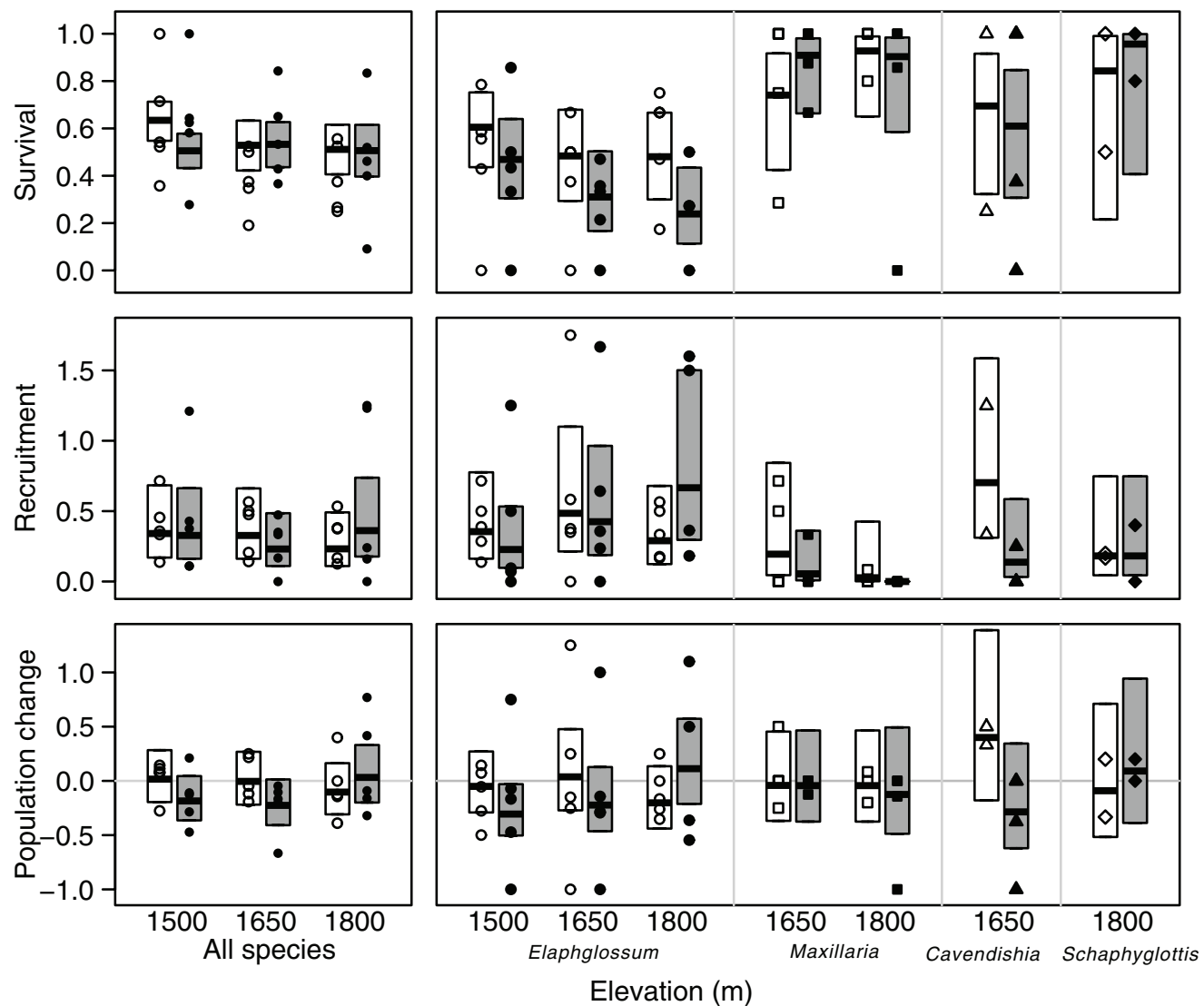

Figure 1. Survival, recruitment, and population change of ramets of all epiphyte species pooled and four abundant epiphyte species from a transplant experiment within three elevations. Points show survival (top), recruitment (middle), and population change (bottom) of individual mats in 2006, each expressed as a proportion relative to the number of ramets present in 2005. Thick horizontal lines and boxes depict the modeled mean and 95\% confidence intervals, respectively. White shading depicts controls, dark shading transplant. 
Table 3. Results of generalized linear mixed-effects models (GLMMs) for all species in mats transplanted within elevations. SE: standard error.

\begin{tabular}{|c|c|c|c|c|}
\hline & Estimate & SE & Statistic & $\mathbf{P}$ \\
\hline \multicolumn{5}{|l|}{ (a) Survival } \\
\hline Intercept & 0.16 & 0.08 & & \\
\hline Treatment & & & $\mathrm{X}_{(1)}^{2}=2.15$ & 0.142 \\
\hline Transplant vs. Control & -0.23 & 0.15 & $z=-1.47$ & 0.143 \\
\hline Elevation & & & $\mathrm{X}_{(2)}^{2}=1.20$ & 0.548 \\
\hline $1650 \mathrm{~m}$ vs. $1500 \mathrm{~m}$ & -0.11 & 0.18 & $z=-0.63$ & 0.530 \\
\hline $1800 \mathrm{~m}$ vs. $1500 \mathrm{~m}$ & -0.20 & 0.19 & $z=-1.07$ & 0.287 \\
\hline 1800 m vs. 1650 m & -0.09 & 0.21 & $z=-0.42$ & 0.675 \\
\hline Treatment $\times$ elevation & & & $\mathrm{X}_{(2)}^{2}=2.86$ & 0.239 \\
\hline \multicolumn{5}{|l|}{ (levels not shown) } \\
\hline Source tree $[R]$ & 0.00 & & & \\
\hline Transplant tree [R] & 0.00 & & & \\
\hline \multicolumn{5}{|l|}{ (b) Recruitment } \\
\hline Intercept & -1.20 & 0.20 & & \\
\hline Treatment & & & $\mathrm{X}_{(1)}^{2}=0.00$ & 0.983 \\
\hline Transplant vs. Control & 0.00 & 0.14 & $z=-0.02$ & 0.982 \\
\hline Elevation & & & $\mathrm{X}_{(2)}^{2}=0.13$ & 0.938 \\
\hline 1650 m vs. 1500 m & -0.17 & 0.49 & $z=-0.35$ & 0.729 \\
\hline $1800 \mathrm{~m}$ vs. $1500 \mathrm{~m}$ & -0.13 & 0.50 & $z=-0.25$ & 0.801 \\
\hline $1800 \mathrm{~m}$ vs. $1650 \mathrm{~m}$ & 0.05 & 0.50 & $z=0.09$ & 0.927 \\
\hline Treatment $x$ elevation & & & $\mathrm{X}_{(2)}^{2}=4.53$ & 0.104 \\
\hline \multicolumn{5}{|l|}{ (levels not shown) } \\
\hline Source tree $[R]$ & 0.47 & & & \\
\hline Transplant tree [R] & 0.56 & & & \\
\hline \multicolumn{5}{|l|}{ (c) Population change } \\
\hline Intercept & -0.08 & 0.06 & & \\
\hline Treatment & & & $\mathrm{X}_{(1)}^{2}=2.18$ & 0.140 \\
\hline Transplant vs. Control & -0.12 & 0.08 & $z=-1.48$ & 0.138 \\
\hline Elevation & & & $\mathrm{X}_{(2)}^{2}=0.32$ & 0.852 \\
\hline $1650 \mathrm{~m}$ vs. $1500 \mathrm{~m}$ & -0.03 & 0.14 & $z=-0.20$ & 0.842 \\
\hline 1800 m vs. 1500 m & 0.05 & 0.14 & $z=0.37$ & 0.710 \\
\hline $1800 \mathrm{~m}$ vs. $1650 \mathrm{~m}$ & 0.08 & 0.14 & $z=0.56$ & 0.575 \\
\hline Treatment $\mathrm{x}$ elevation & & & $\mathrm{X}_{(2)}^{2}=4.45$ & 0.108 \\
\hline (levels not shown) & & & & \\
\hline Source tree $[R]$ & 0.13 & & & \\
\hline Transplant tree $[\mathrm{R}]$ & 0.10 & & & \\
\hline
\end{tabular}

$[R]$ indicates random effect.

mats transplanted to $1500 \mathrm{~m}$ (Figure 2). There were no significant effects of source elevation or transplant elevation on survival or population change (Table 6), but survival was lower and population change more negative for ramets transplanted to $1500 \mathrm{~m}$ (Figure 2).

All three measures of performance were unaffected by transplant elevation in Cavendishia (Table 6, Figure 2). For Schaphyglottis, survival, recruitment, and population change were all progressively lower in mats transplanted to lower elevations (Figure 2), but the difference was significant only for survival (Table 6).

\section{Community composition}

Prior to transplanting mats, the epiphyte community composition showed significant differences across the elevational gradient, although relatively little of the variation could be explained by elevation (Table 7); most of the compositional separation was between mats at $1500 \mathrm{~m}$ and the other two elevations (Figure 3). Morphospecies richness increased with elevation (Poisson regression, $\mathrm{Z}=2.446, P=0.0144$ ), while the number of ramets per mat declined (Poisson regression, $\mathrm{Z}=-2.281, P=0.0225$; Table 8). Comparison of pre- and post-treatment species compositions in mats revealed no directional shift in community composition due to transplantation (Table 7). A few mats did show large changes (Figure 3), likely because of large changes in abundance in Elaphoglossum, either through high ramet mortality or recruitment (Figure 2).

\section{Discussion}

Vascular epiphytes transplanted down slope from our highest elevation had lower demographic performance when transplanted to the lowest elevation, suggesting warmer temperatures and lower cloud immersion will cause community-level changes for species currently above the cloud base. This result corroborates previous work in another tropical montane site, which found fewer leaves and shorter life-spans for vascular epiphytes moved down slope ${ }^{29}$. However, reciprocal transplants between all elevations revealed unexpected dynamics, with demographic rates differing in their response and species responding individualistically to the treatments, perhaps reflecting functional type differences (Figure 2). Cavendishia, a small woody shrub showed the least response, while Elaphoglossum, a strap-leafed fern in which individual leaves were the measurement unit was most responsive to treatments. The two orchid species were intermediate, with Schaphyglottis responding more strongly than Maxillaria which has stouter stems. Thus, functional differences in ramet construction may account for the differences in response among species to the elevational transplants. In general, it appears that epiphytes responded to water stress but we also found evidence for local adaptation. This response to transplanting was strongest in those transplanted from the highest elevation, which has the highest degree of cloud immersion. Epiphytes from lower elevations only benefitted slightly from increased water availability, possibly indicating they are better adapted to withstand drought stress. Epiphytes from the middle elevations, where cloud immersion is intermediate, responded in more idiosyncratic ways to transplantation. Finally, while composition changed across the elevational gradient, there was no significant directional shift in composition due to any of the transplant treatments (Figure 3, Table 7). The relative resistance of epiphytes to expected transplant-induced moisture stress found in this study could be due to two competing factors, described below in more detail: (1) rainfall compensation in this pluvial system, where high rainfall is sufficient to maintain epiphyte water-balance below cloud base; and/or (2) higher epiphyte drought tolerance from a history of variable rainfall and occasional drought in these continental mountains.

\section{Rainfall compensation}

While our results for epiphytes transplanted from the highest elevation are consistent with the hypothesized altitudinal gradient in moisture stress, this gradient had less of an effect on epiphyte performance than the one in Monteverde, Costa $\mathrm{Rica}^{29}$. The relative importance of cloud immersion for the distribution of epiphytes 


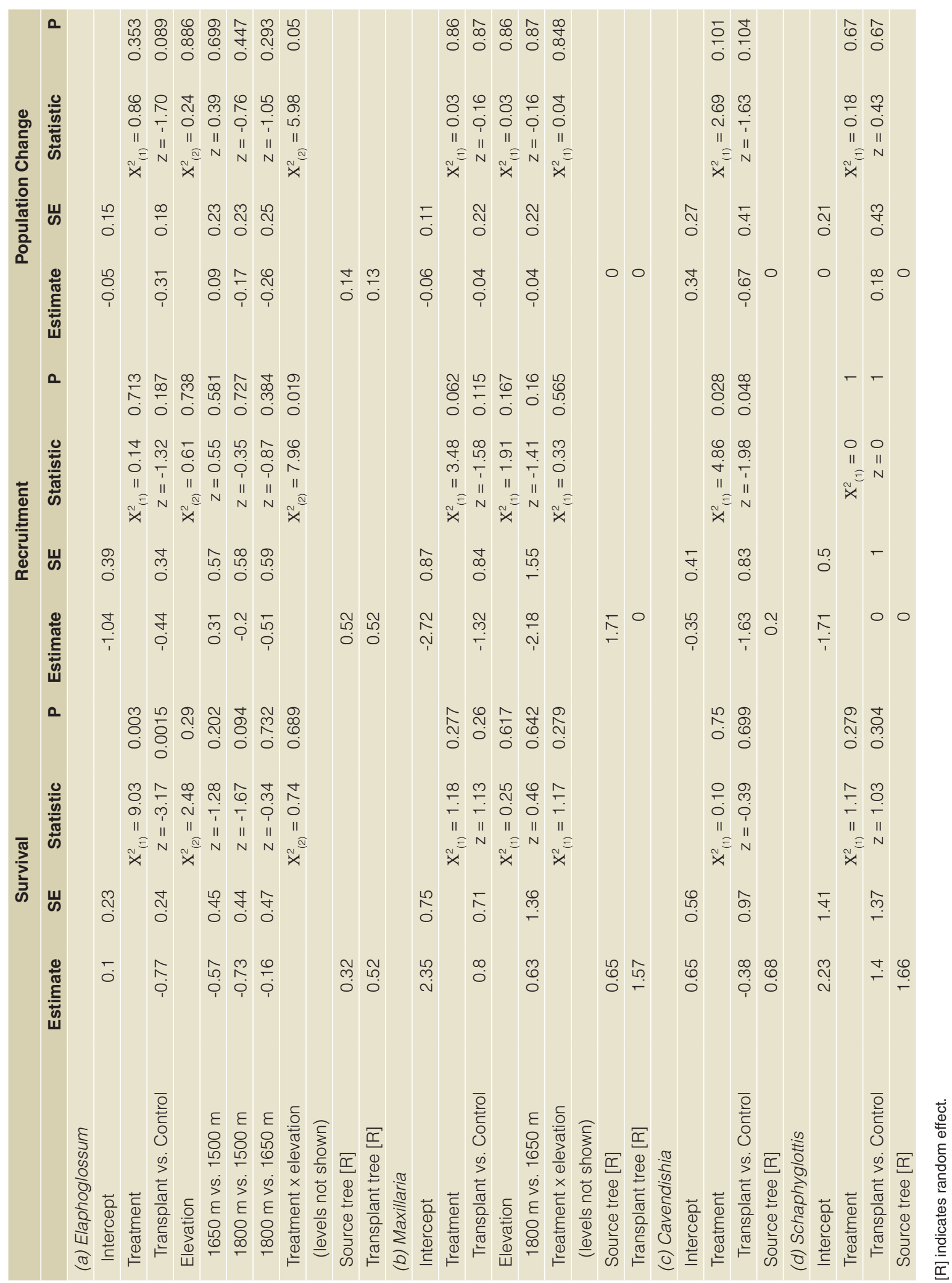



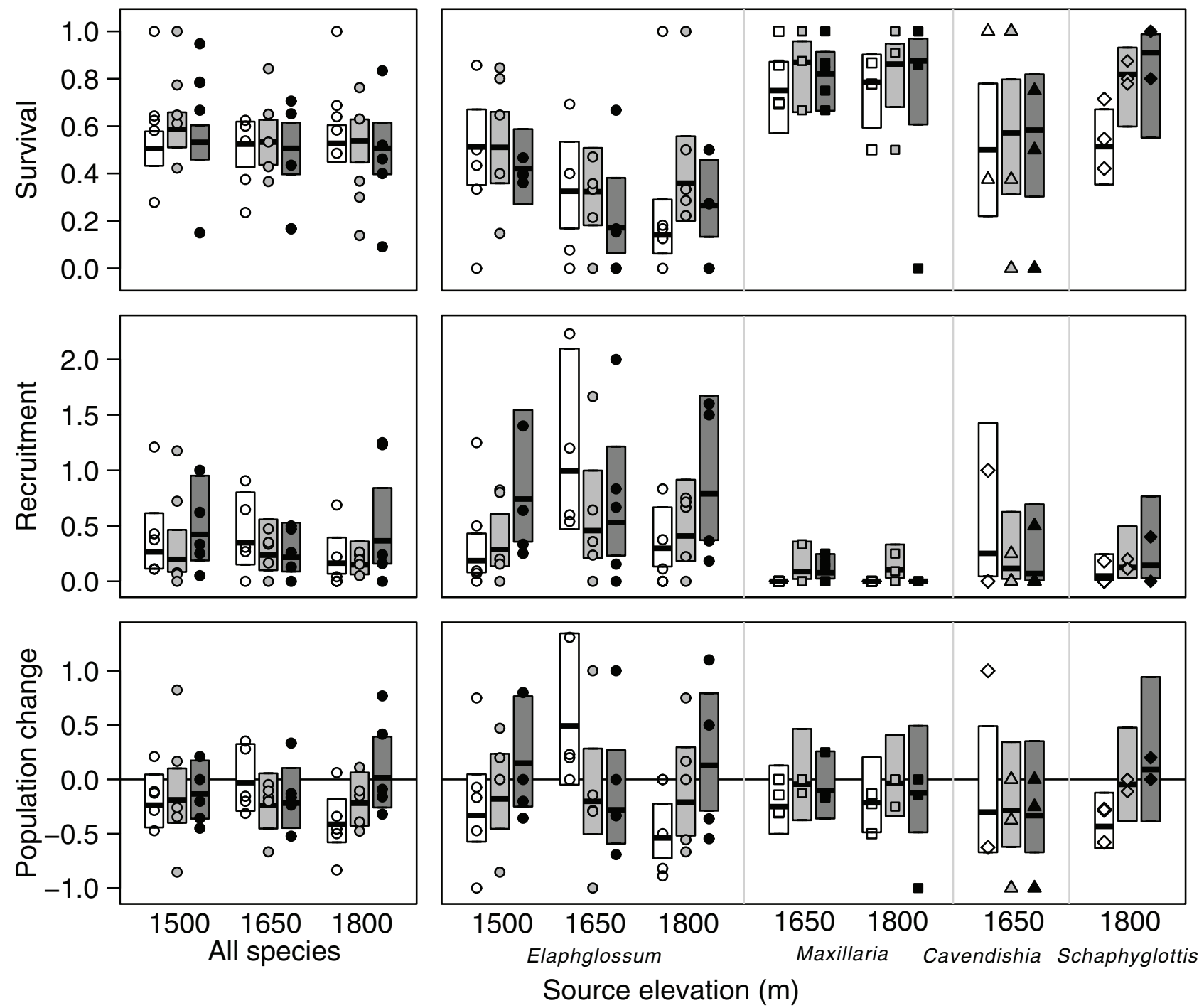

Figure 2. Survival, recruitment, and population change of epiphyte ramets from a reciprocal transplant experiment across three elevations. Points show survival (top), recruitment (middle), and population change (bottom) of individual mats in 2006, each expressed as a proportion relative to the number of ramets present in 2005. Thick horizontal lines and boxes depict the modeled mean and $95 \%$ confidence intervals, respectively. White shading depicts 1500 m elevation, light grey $1650 \mathrm{~m}$ elevation and dark grey $1800 \mathrm{~m}$ elevation. 


\begin{tabular}{|c|c|c|c|c|}
\hline & Estimate & SE & Statistic & $\mathbf{P}$ \\
\hline \multicolumn{5}{|l|}{ (a) Survival } \\
\hline Intercept & 0.13 & 0.06 & & \\
\hline Source elevation & & & $\mathrm{X}_{(2)}^{2}=0.31$ & 0.858 \\
\hline $1650 \mathrm{~m}$ vs. $1500 \mathrm{~m}$ & -0.07 & 0.15 & $z=-0.50$ & 0.619 \\
\hline $1800 \mathrm{~m}$ vs. $1500 \mathrm{~m}$ & -0.06 & 0.14 & $z=-0.41$ & 0.683 \\
\hline $1800 \mathrm{~m}$ vs. $1650 \mathrm{~m}$ & 0.02 & 0.16 & $z=0.11$ & 0.916 \\
\hline Transplant elevation & & & $\mathrm{X}^{2}{ }_{(2)}=1.64$ & 0.440 \\
\hline $1650 \mathrm{~m}$ vs. $1500 \mathrm{~m}$ & 0.16 & 0.14 & $z=1.17$ & 0.241 \\
\hline $1800 \mathrm{~m}$ vs. $1500 \mathrm{~m}$ & 0.01 & 0.14 & $z=0.07$ & 0.947 \\
\hline $1800 \mathrm{~m}$ vs. $1650 \mathrm{~m}$ & -0.15 & 0.15 & $z=-1.03$ & 0.301 \\
\hline Source elevation $\times$ transplant elevation & & & $\mathrm{X}_{(4)}^{2}=1.09$ & 0.895 \\
\hline \multicolumn{5}{|l|}{ (levels not shown) } \\
\hline Source tree $[R]$ & 0.00 & & & \\
\hline Transplant tree $[R]$ & 0.00 & & & \\
\hline \multicolumn{5}{|l|}{ (b) Recruitment } \\
\hline Intercept & -1.33 & 0.42 & & \\
\hline Source elevation & & & $\mathrm{X}_{(2)}^{2}=0.41$ & 0.816 \\
\hline $1650 \mathrm{~m}$ vs. $1500 \mathrm{~m}$ & 0.27 & 0.48 & $z=0.57$ & 0.570 \\
\hline $1800 \mathrm{~m}$ vs. $1500 \mathrm{~m}$ & -0.48 & 0.51 & $z=-0.94$ & 0.345 \\
\hline $1800 \mathrm{~m}$ vs. $1650 \mathrm{~m}$ & -0.46 & 0.51 & $z=-0.89$ & 0.373 \\
\hline Transplant elevation & & & $\mathrm{X}_{(2)}^{2}=2.37$ & 0.305 \\
\hline $1650 \mathrm{~m}$ vs. $1500 \mathrm{~m}$ & -0.29 & 0.42 & $z=-0.69$ & 0.492 \\
\hline $1800 \mathrm{~m}$ vs. $1500 \mathrm{~m}$ & 0.47 & 0.40 & $z=1.16$ & 0.244 \\
\hline $1800 \mathrm{~m}$ vs. $1650 \mathrm{~m}$ & -0.09 & 0.46 & $z=-0.20$ & 0.845 \\
\hline Source elevation $\times$ transplant elevation & & & $X^{2}{ }_{(4)}=13.31$ & 0.010 \\
\hline \multicolumn{5}{|l|}{ (levels not shown) } \\
\hline Source tree $[R]$ & 0.66 & & & \\
\hline Transplant tree [R] & 0.53 & & & \\
\hline \multicolumn{5}{|l|}{ (c) Population change } \\
\hline Intercept & -0.27 & 0.16 & & \\
\hline Source elevation & & & $\mathrm{X}_{(2)}^{2}=0.30$ & 0.860 \\
\hline $1650 \mathrm{~m}$ vs. $1500 \mathrm{~m}$ & 0.24 & 0.18 & $z=1.36$ & 0.174 \\
\hline $1800 \mathrm{~m}$ vs. $1500 \mathrm{~m}$ & -0.26 & 0.19 & $z=-1.41$ & 0.157 \\
\hline $1800 \mathrm{~m}$ vs. $1650 \mathrm{~m}$ & 0.03 & 0.18 & $z=0.15$ & 0.885 \\
\hline Transplant elevation & & & $\mathrm{X}^{2}{ }_{(2)}=1.03$ & 0.597 \\
\hline $1650 \mathrm{~m}$ vs. $1500 \mathrm{~m}$ & 0.06 & 0.19 & $z=0.33$ & 0.742 \\
\hline $1800 \mathrm{~m}$ vs. $1500 \mathrm{~m}$ & 0.13 & 0.19 & $z=0.67$ & 0.506 \\
\hline $1800 \mathrm{~m}$ vs. $1650 \mathrm{~m}$ & 0.03 & 0.21 & $z=0.13$ & 0.898 \\
\hline $\begin{array}{l}\text { Source elevation } \times \text { transplant elevation } \\
\text { (levels not shown) }\end{array}$ & & & $\mathrm{X}_{(4)}^{2}=13.57$ & 0.009 \\
\hline Source tree $[R]$ & 0.17 & & & \\
\hline Transplant tree $[\mathrm{R}]$ & 0.21 & & & \\
\hline
\end{tabular}

$[R]$ indicates random effect. 


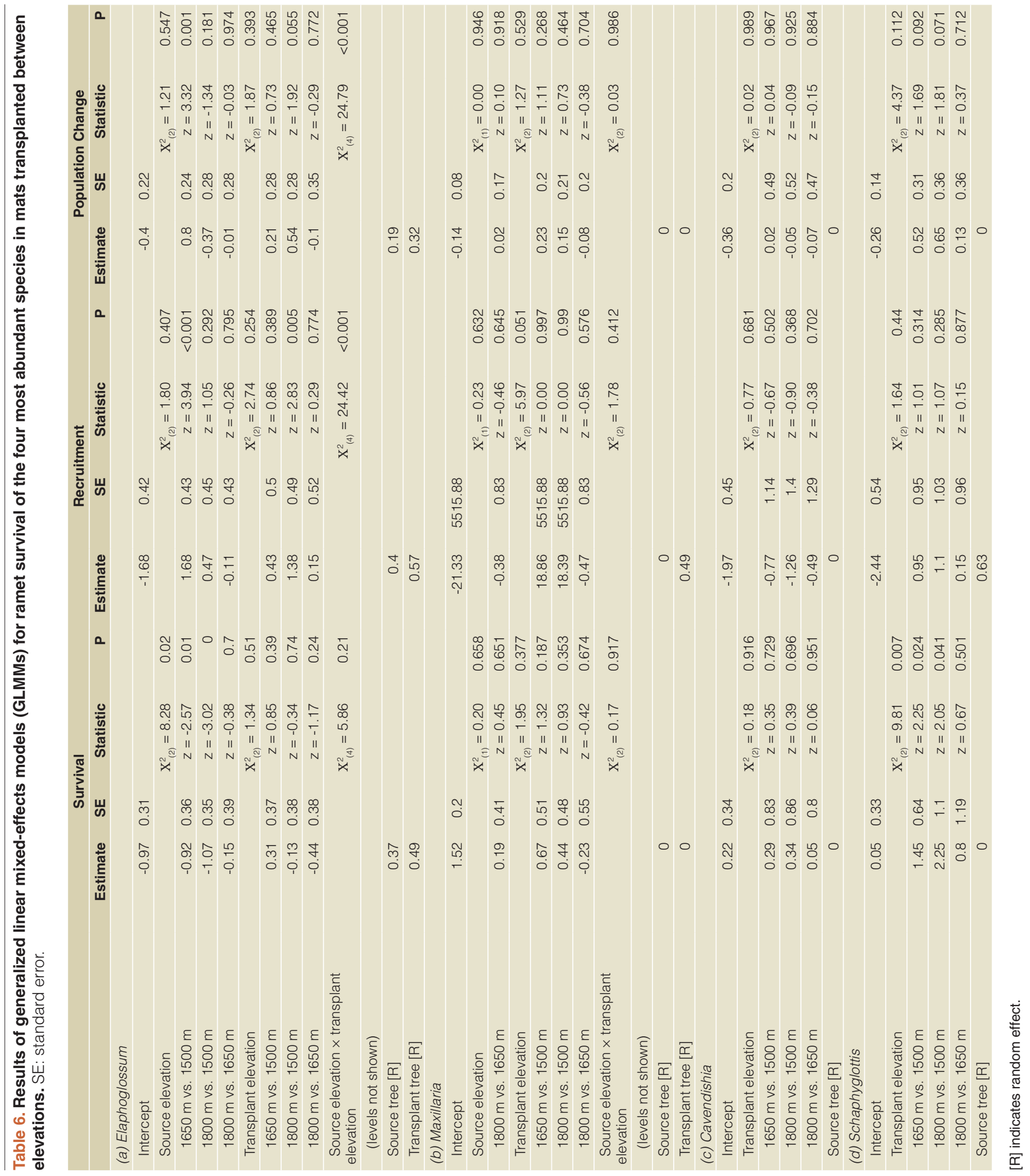




\begin{abstract}
Table 7. ANOVA table from permutational multivariate Analysis of Variance to test differences in composition between mats at different elevations across years and treatments.
\end{abstract}

\begin{tabular}{|llllll|}
\hline Source of variation & df & SS & MS & F & R2 \\
\hline Elevation & 1 & 0.75 & 0.75 & 3.38 & $0.0283^{* *}$ \\
\hline Treatment & 1 & 0.25 & 0.25 & 1.14 & 0.0095 \\
\hline Year & 1 & 0.071 & 0.07 & 0.32 & 0.0027 \\
\hline Elevation $\times$ Treatment & 1 & 0.17 & 0.17 & 0.74 & 0.0062 \\
\hline Elevation $\times$ Year & 1 & 0.31 & 0.31 & 1.40 & 0.0117 \\
\hline Treatment $\times$ Year & 1 & 0.04 & 0.04 & 0.20 & 0.0016 \\
\hline Elevation $\times$ Treatment $\times$ Year & 1 & 0.10 & 0.10 & 0.44 & 0.0037 \\
\hline Residuals & 112 & 24.92 & 0.22 & & 0.9363 \\
\hline Total & 119 & 26.61 & & & 1
\end{tabular}

Significance levels: ${ }^{*} \mathrm{p}<0.01$.

in this system may account for the difference. A consistent cloud base is a significant feature of many tropical montane forests ${ }^{2,54}$, and regular low cloud is assumed to maintain the diversity and abundance of cloud forest epiphytes, and control many of the unique structural and functional features of cloud forests ${ }^{43,44}$. Indeed, we chose the elevations for this experiment because of a suite of changes in ecosystem structure and function that occur at these elevations, including a step-change in bryophyte and vascular epiphyte biomass ${ }^{40}$, tree height, above ground biomass, and forest productivity declining $^{42}$, and soil organic matter increasing ${ }^{41}$ above $1500 \mathrm{~m}$. Tree diversity also begins to decline above $1500 \mathrm{~m}$ in the study region ${ }^{55,56}$ mimicking the general pattern in the Andes ${ }^{57,58}$. These clear changes in forest structure, diversity and productivity contrast with smoother changes in climate. Mean temperature, precipitation, and VPD, a measure of moisture stress on plants, all decrease linearly with elevation above $1000 \mathrm{~m}^{46}$.

High rainfall in this part of the Andes may mean that epiphytes here are less dependent on cloud immersion to maintain their water balance than their counterparts in other cloud forests. Even in 2005 under drought conditions, total precipitation for the year was $3273 \mathrm{~mm}$. In this pluvial system, cloud base may be less important in determining epiphyte distributions than in other systems. It is noteworthy that the Nadkarni and Solano ${ }^{29}$ experiment was carried out on the leeward Pacific slope of Monteverde, which is drier than the Caribbean slope $^{59,60}$. Mean annual precipitation on the Pacific slope is $2155 \mathrm{~mm}$ at $1480 \mathrm{~m}$ in the cloud forest ${ }^{61}$, and declines at lower elevations ${ }^{60}$, and there is a 5-6 month dry season where much of the hydrologic balance is maintained by cloud immersion ${ }^{61}$. This steep moisture gradient between cloud forest and lower elevations probably leads to a greater dependence of epiphytes on cloud immersion. If this previous study had been carried out on the Caribbean slope, where precipitation is higher at lower elevation ${ }^{60}$, the results may have been similar to our study. On leeward slopes rainfall compensation may occur, in which epiphyte survival is enhanced by high rainfall even when there is less frequent cloud immersion.

\section{Drought tolerance}

Even though high rainfall may maintain epiphytes under normal conditions in the eastern Andes, droughts do occur, and epiphytes may be adapted to infrequent drought, especially at the lower fringe of the cloud forest. Drought in the Amazon basin during $2005^{62-64}$ resulted in lower precipitation in the cloud forest. Rainfall at the Peruvian SENAMHI meterological station at Rocotal $\left(13^{\circ} 06^{\prime} 41^{\prime \prime} \mathrm{S}, 71^{\circ} 34^{\prime} 14^{\prime \prime}\right.$, approximately $7 \mathrm{~km}$ from the transplant site at 2010 m elevation) for May-August in 2005 was the lowest for any year measured (mean May-August precipitation for 2000-2008: $601 \mathrm{~mm}$; 2005: $175 \mathrm{~mm}$ ). There was no recorded rainfall in July 2005 , the only month during the nine-year measurement period with no recorded precipitation (mean July precipitation: $112 \mathrm{~mm}$ ). In addition, actual cloud water interception based on fog collectors in place during the experiment did not show a gradient of increasing moisture with elevations during the 2005 dry season (four week total weight of water collected: $1500 \mathrm{~m}, 1109 \mathrm{~g} \mathrm{~m}^{-2} ; 1750 \mathrm{~m}, 35 \mathrm{~g} \mathrm{~m}^{-2}$; $1900 \mathrm{~m}, 72 \mathrm{~g} \mathrm{~m}^{-2}$ ). All elevations were very dry, and desiccation was evident in bryophytes and non-succulent vascular epiphytes in the study area. However, ramet mortality in undisturbed control mats was not significantly greater than recruitment at any elevation (Figure 1). In addition, mat species composition did not change directionally between years (Figure 3). Thus, undisturbed epiphytes between 1500 and $1800 \mathrm{~m}$ in this Andean cloud forest appeared resistant to drought over the one-year time scale of our experiment.

This resistance to drought may be related to the normally variable and seasonal rainfall at the study site. Annual rainfall totals ranged between 3 and $6 \mathrm{~m}$ per year in a five year period not including the 2005 Amazonian drought. Precipitation was lowest in June and $\mathrm{July}^{46}$, when temporary drought is possible, though for no month did PET exceed precipitation at these elevations in most years. However, prolonged (days-to-weeks) periods of direct sun can induce drought stress, and epiphyte species that live in this part of the Andes may possess adaptations for surviving drought, similar to those in lowland dry or seasonal forests ${ }^{36,37,65}$. Epiphyte drought 


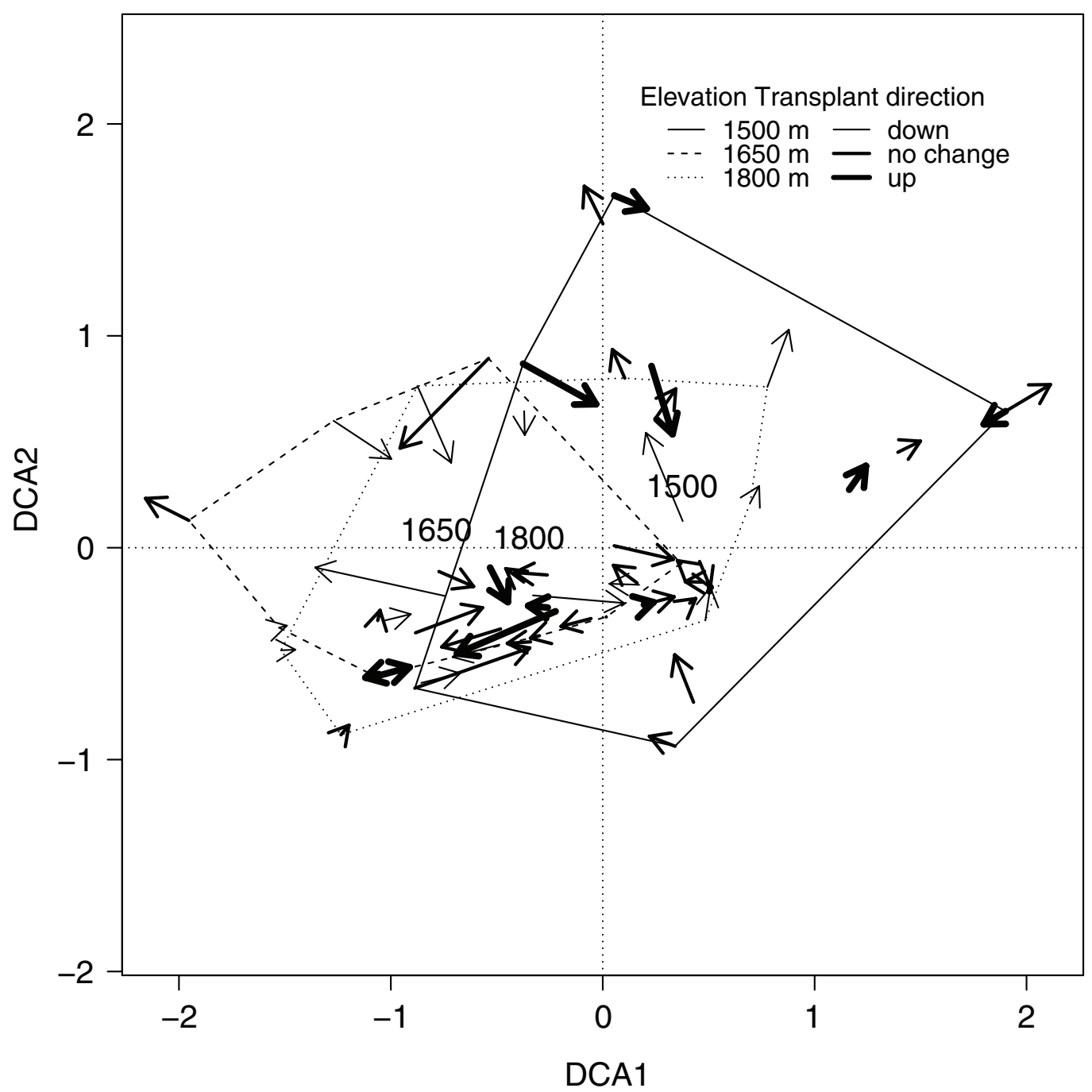

Figure 3. First two axis of a Detrended Correspondance Analysis (DCA) on the species composition of epiphyte mats both before and after mats were transplanted. Arrows connect the compositions of individual mats before and a year after transplantation. Line width depicts direction of transplanting. Hulls are drawn around the 2005 composition of mats that originated at the same elevation, and labels are placed at the hull centroid.

Table 8. Species richness or morpho-species and ramet density of mats surveyed in 2005. Per mat values are means with standard error in parentheses.

\begin{tabular}{|llll|}
\hline Elevation $(\mathbf{m})$ & Total species & Species per mat & Ramets per mat \\
\hline 1500 & 13 & $2.35(1.04)$ & $27.70(11.20)$ \\
\hline 1650 & 14 & $3.65(1.14)$ & $20.75(6.82)$ \\
\hline 1800 & 16 & $3.75(1.16)$ & $24.15(11.81)$ \\
\hline
\end{tabular}


tolerance is higher in areas where drought occurs more frequently ${ }^{19,66}$, and many epiphyte species have adaptations for surviving drought crassulacean acid metabolism, desiccation tolerance, pseudobulbs, succulent leaves and other water-storing organs. Consistent with this idea, Elaphoglossum ramets transplanted from $1500 \mathrm{~m}$ had higher survival than those from higher elevations, regardless of the transplant elevation (Figure 2). The stronger response of epiphyte mats transplanted from normally cloud immersed elevations (i.e. $1800 \mathrm{~m}$ ) compared to those transplanted from lower elevations suggests that lower elevation populations may be better adapted to drought stress due to less frequent cloud immersion. Another example of locally adapted epiphytes was observed in subtropical China, where bryophytes transplanted downslope lost biomass, while in situ measurements showed no change in biomass across the gradient ${ }^{38}$.

\section{Conclusion}

Greater epiphyte resistance to drought in this part of the Andes compared to previous studies may indicate that even seemingly benign dry seasons or dry periods can be important for structuring epiphyte communities, with potential implications for larger scale patterns of diversity. More generally, while epiphyte response to global climate change on tropical mountains is discussed in the literature ${ }^{18,19,29,38}$, tropical mountains and their climates are highly heterogeneous, and predictions may defy all but the broadest generalizations. Fundamental differences in the climate and biogeographical contexts may lead to differences in species response to climate change. Long-term experimental studies in tropical montane systems are needed to understand the drivers of patterns of epiphyte abundance, in particular why there is a change in biomass and abundance at putative 'cloud base' (which is correlated with changes throughout the ecosystem), and how these diverse communities will respond to climate change. While our experiment suggests that epiphytes in our study system show some resistance to climate change, climate models predict more severe droughts in parts of the Andes ${ }^{20,21}$. Pervasive changes in the tree canopy of the western Amazon following the 2005 Amazon drought persisted until an even stronger drought in $2010^{67}$; it is unknown whether similarly long-lasting effects were present in Andean cloud forest.
Given the keystone position of epiphytes in cloud forests, droughtinduced changes in epiphyte communities could have cascading effects throughout the ecosystem.

\section{Data availability}

Figshare: Survey of epiphytes before and after transplantation across an altitudinal gradient of increasing cloud immersion along the eastern slope of the Andes, Peru, http://dx.doi.org/10.6084/ m9.figshare. $894979^{68}$.

\section{Author contributions}

JMR and MRS conceived and designed the experiments. JMR performed the experiments and analyzed the data. JMR and MRS wrote the manuscript. The authors declare that the experiments described comply with the current laws of Peru.

\section{Competing interests}

No competing interests were disclosed.

\section{Grant information}

Funding was generously provided by a Wake Forest University Biology Department Vecellio Fund grant to J.M. Rapp, and grants from the Gordon and Betty Moore Foundation Andes to Amazon Program, NSF EAR 0711414, NSF DEB-0237684, and an NSF REU supplement DEB-0237684 to M.R. Silman.

The funders had no role in study design, data collection and analysis, decision to publish, or preparation of the manuscript.

\section{Acknowledgements}

This paper is a product of the Andes Biodiversity and Ecosystem Research Group (ABERG). We would like to thank Norma Salinas for help with permits, the Cock-of-the-Rock Lodge for letting us set up the experiment on their land, Luis Imunda for clearing a trail, Richard Amick for helping with canopy access, and William Farfan for species identification. 


\section{Supplementary materials}

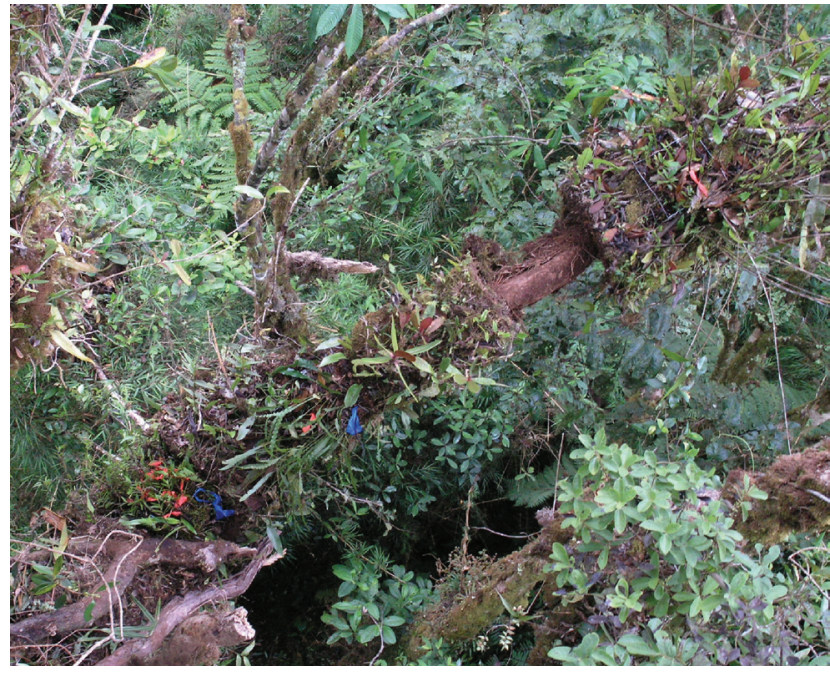

Figure S1. Study branch. Experimental mats in a tree at $1800 \mathrm{~m}$ were all on the same large horizontal branch. From lower left to upper right: two mats transplanted from trees at 1500 and $1650 \mathrm{~m}$, an open space awaiting a transplanted mat from $1800 \mathrm{~m}$, and a surveyed undisturbed control mat.

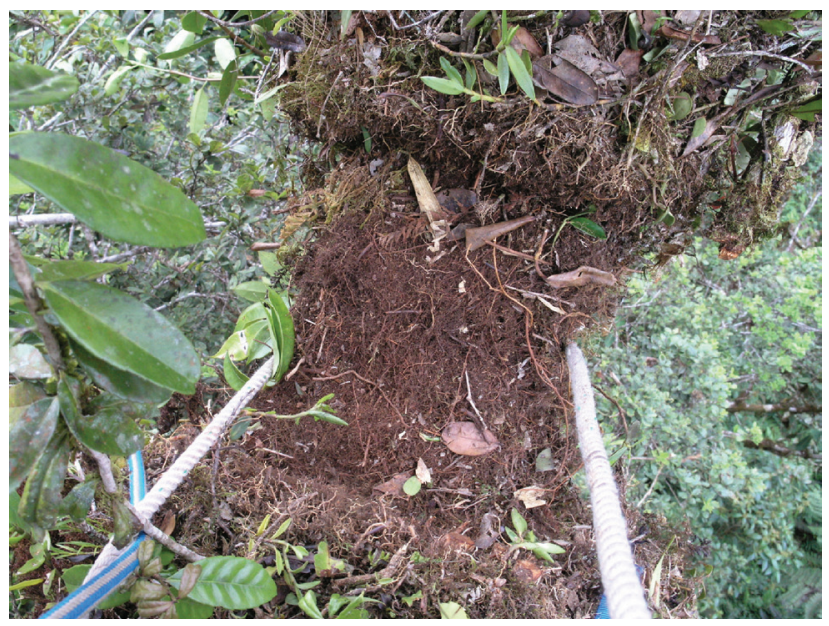

Figure S2. Mat removed. A transplanted mat was removed from this branch at $1650 \mathrm{~m}$.

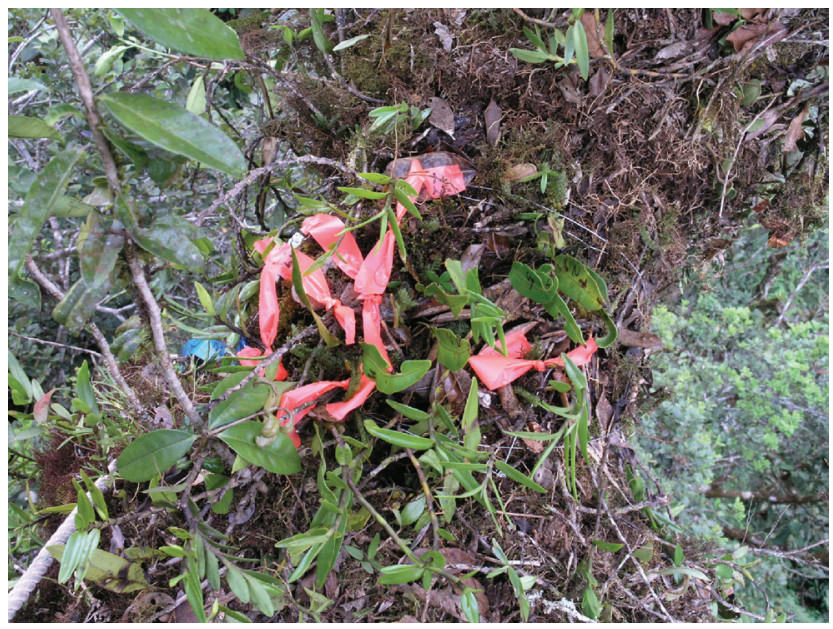

Figure S3. Transplanted mat. A mat from another tree was transplanted into the same location.

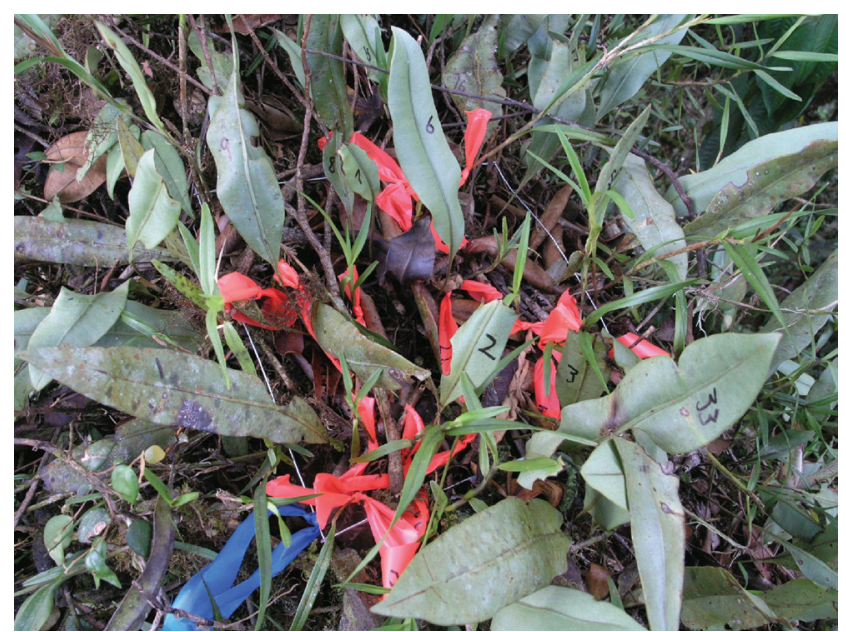

Figure S4. Control mat. A control epiphyte mat after being surveyed in 2005. This mat at $1800 \mathrm{~m}$ elevation included primarily Elaphoglossum and Schaphyglottis. 
1. Foster $P$ : The potential negative impacts of global climate change on tropical montane cloud forests. Earth Sci Rev. 2001; 55(1-2): 73-106. Publisher Full Text

2. Loope LL, Giambelluca TW: Vulnerability of island tropical montane cloud forests to climate change, with special reference to East Maui, Hawaii. Clim Change. 1998; 39(2-3): 503-517.

Publisher Full Text

3. Herzog S, Martinez R, Jorgensen P, et al:: Climate change and biodiversity in the tropical Andes. Inter-American Institute for Global Change Research (IAI) and Scientific Committee on Problems of the Environment (SCOPE) 2011 Reference Source

4. Myers N, Mittermeier RA, Mittermeier CG, et al.: Biodiversity hotspots for conservation priorities. Nature. 2000; 403(6772): 853-858.

Publisher Full Text

5. Gentry AH: Tropical Forest Biodiversity-Distributional Patterns and Their Conservational Significance. Oikos. 1992; 63(1): 19-28.

Reference Source

6. Knapp S: Assessing patterns of plant endemism in neotropical uplands. Bot Rev. 2002; 68(1): 22-37.

Publisher Full Text

7. Kuper W, Kreft H, Nieder J, et al.: Large-scale diversity patterns of vascular epiphytes in Neotropical montane rain forests. J Biogeogr. 2004; 31(9): 1477-1487.

Publisher Full Text

8. Cruz-Angon A, Baena ML, Greenberg R: The contribution of epiphytes to the abundance and species richness of canopy insects in a Mexican coffee plantation. J Trop Ecol. 2009; 25(5): 453-463.

Publisher Full Text

9. Cruz-Angon A, Greenberg R: Are epiphytes important for birds in coffee plantations? An experimental assessment. J Appl Ecol. 2005; 42(1): 150-159. Publisher Full Text

10. Nadkarni NM, Matelson TJ: Bird Use of Epiphyte Resources in Neotropical Trees. Condor. 1989; 91(4): 891-907.

Reference Source

11. Yanoviak SP, Nadkarni NM, Solano R: Arthropod assemblages in epiphyte mats of Costa Rican cloud forests. Biotropica. 2007; 39(2): 202-210. Publisher Full Text

12. Gomez-Peralta D, Oberbauer SF, McClain ME, et al:: Rainfall and cloud-water interception in tropical montane forests in the eastern Andes of Central Peru. For Ecol Manage. 2008; 255(3-4): 1315-1325.

Publisher Full Text

13. Holscher D, Kohler L, van Dijk A, et al.: The importance of epiphytes to total rainfal interception by a tropical montane rain forest in Costa Rica. $J$ Hydrol. 2004; 292(1-4): 308-322.

Publisher Full Text

14. Munoz-Villers LE, Holwerda F, Gomez-Cardenas M, et al:: Water balances of oldgrowth and regenerating montane cloud forests in central Veracruz, Mexico. J Hydrol. 2012; 462: 53-66. Publisher Full Text

15. Nadkarni NM, Schaefer D, Matelson TJ, et al.: Biomass and nutrient pools of canopy and terrestrial components in a primary and a secondary montane cloud forest, Costa Rica. For Ecol Manage. 2004; 198(1-3): 223-236. Publisher Full Text

16. Umana NHN, Wanek W: Large canopy exchange fluxes of inorganic and organic nitrogen and preferential retention of nitrogen by epiphytes in a tropical lowland rainforest. Ecosystems. 2010; 13(3): 367-381. Publisher Full Text

17. Weathers KC: The importance of cloud and fog in the maintenance of ecosystems. Trends Ecol Evol. 1999; 14(6): 214-215. PubMed Abstract | Publisher Full Text

18. Benzing DH: Vulnerabilities of tropical forests to climate change: The significance of resident epiphytes. Clim Change. 1998; 39(2-3): 519-540. Publisher Full Text

19. Zotz G, Bader MY: Epiphytic Plants in a Changing World: Global Change Effects on Vacular and Non-vascular Epiphytes, in Progress in Botany, U. Lüttge, et al., Editors. Springer-Verlag: Berlin Heidelberg. 2009; 70; 147-170. Publisher Full Text

20. Neelin JD, Munnich M, Su H, et al.: Tropical drying trends in global warming models and observations. Proc Nat Acd Sci. 2006; 103(16): 6110-6115. Publisher Full Text

21. Urrutia R, Vuille M: Climate change projections for the tropical Andes using a regional climate model: Temperature and precipitation simulations for the end of the 21st century. J Geophys Res Atmos. 2009; 114(D2). Publisher Full Text

22. Vuille $M$, Francou $B$, Wagnon $P$, et al.: Climate change and tropical Andean glaciers: Past, present and future. Earth Sci Rev. 2008; 89(3-4): 79-96. Publisher Full Text

23. Martinez R, Ruiz D, Andrade M, et al.: Synthesis of the climate of the tropica Andes, in Climate change and biodiversity in the tropical Andes, SK Herzog, et al., Editors. Inter-American Institute for Global Change Research (IAI) and Scientific Committee on Problems of the Environment (SCOPE) 2011. Reference Source
24. Cowling SA, Shin $\mathrm{Y}$, Pinto $\mathrm{E}$, et al:: Water recycling by Amazonian vegetation: coupled versus uncoupled vegetation-climate interactions. Philos Trans $R$ Soc Lond $B$ Biol Sci. 2008; 363(1498): 1865-1871.

PubMed Abstract | Publisher Full Text | Free Full Text

25. Pinto $E$, Shin $Y$, Cowling SA, et al:: Past, present and future vegetation-cloud feedbacks in the Amazon Basin. Clim Dynamics. 2009; 32(6): 741-751. Publisher Full Text

26. Still CJ, Foster PN, Schneider SH: Simulating the effects of climate change on tropical montane cloud forests. Nature. 1999; 398(6728): 608-610. Publisher Full Text

27. Pounds JA, Fogden MPL, Campbell JH: Biological response to climate change on a tropical mountain. Nature. 1999; 398(6728): 611-615. Publisher Full Text

28. Anchukaitis KJ, Evans MN: Tropical cloud forest climate variability and the demise of the Monteverde golden toad. Proc Natl Acad Sci U S A. 2010; 107(11): 5036-5040.

PubMed Abstract | Publisher Full Text | Free Full Text

29. Nadkarni NM, Solano R: Potential effects of climate change on canopy communities in a tropical cloud forest: an experimental approach. Oecologia. 2002; 131(4): 580-586.

Publisher Full Text

30. Hamilton LS, Juvik JO, Scatena FN: The Puerto Rico Tropical Cloud Forest Symposium: Introduction and Workshop Synthesis, in Tropical Montane Cloud Forests, LS Hamilton, JO Juvik, and FN Scatena, Editors. Springer-Verlag: New York 1994 Reference Source

31. Stadtmuller T: Cloud Forests in the Humid Tropics: A Bibliographic Review. Centro Agronómico Tropical de Investigación y Enseñanza: Turrialba, Costa Rica: United Nations University Press: Tokyo. 1987; 82. Reference Source

32. Bruijnzeel LA: Hydrological functions of tropical forests: not seeing the soil for the trees. Agric Ecosystems Environ. 2004; 104(1): 185-228. Publisher Full Text

33. Lawton RO, Nair US, Pielke Sr RA, et al.: Climatic impact of tropical lowland deforestation on nearby montane cloud forests. Science. 2001; 294(5542): 584-587.

PubMed Abstract | Publisher Full Text

34. Pounds JA, Bustamante MR, Coloma LA, et al:: Widespread amphibian extinctions from epidemic disease driven by global warming. Nature. 2006; 439(7073): 161-167.

PubMed Abstract | Publisher Full Tex

35. Killeen TJ, Douglas M, Consiglio T, et al.: Dry spots and wet spots in the Andean hotspot. J Biogeogr. 2007; 34(8): 1357-1373. Publisher Full Text

36. Andrade JL: Dew deposition on epiphytic bromeliad leaves: an important event in a Mexican tropical dry deciduous forest. J Trop Ecol. 2003; 19(5): 479-488.

Publisher Full Text

37. Bader MY, Menke G, Zotz G: Pronounced drought tolerance characterizes the early life stages of the epiphytic bromeliad Tillandsia flexuosa. Funct Ecol. 2009; 23(3): 472-479. Publisher Full Text

38. Song L, Liu WY, Nadkarni NM: Response of non-vascular epiphytes to simulated climate change in a montane moist evergreen broad-leaved forest in southwest China. Biol Conserv. 2012; 152: 127-135. Publisher Full Text

39. Malhi Y, Silman M, Salinas N, et al.: Introduction: Elevation gradients in the tropics: laboratories for ecosystem ecology and global change research. Glob Chang Biol. 2010; 16(12): 3171-3175.

Publisher Full Text

40. Horwath AB: Epiphytic Bryophytes as Cloud Forest Indicators: Stable Isotopes, Biomass and Diversity along an Altitudinal Gradient in Peru. Ph.D. Thesis, University of Cambridge: Cambridge, U.K. 2011; 1-284.

41. Zimmermann M, Meir P, Bird Ml, et al:: Climate dependence of heterotrophic soil respiration from a soil-translocation experiment along a $\mathbf{3 0 0 0} \mathrm{m}$ tropical forest altitudinal gradient. Eur J Soil Sci. 2009; 60(6): 895-906. Publisher Full Text

42. Girardin CAJ, Malhi Y, Aragao LEOC, et al.: Net primary productivity allocation and cycling of carbon along a tropical forest elevational transect in the Peruvian Andes. Glob Chang Biol. 2010; 16(12): 3176-3192. Publisher Full Text

43. Frahm JP, Gradstein SR: An Altitudinal Zonation of Tropical Rain-Forests Using Byrophytes. J Biogeogr. 1991; 18(6): 669-678. Publisher Full Text

44. Grubb PJ: Factors controlling the distribution of forest types on tropical mountains: new facts and a new perspective, in Altitudinal zonationin Malesia, JR Flenley, Editor, University of Hull, Department of Geography: Hull, England. 1974; 13-46.

45. Zimmermann M, Meir $\mathrm{P}$, Bird Ml, et al:: Temporal variation and climate dependence of soil respiration and its components along a $3000 \mathrm{~m}$ altitudinal tropical forest gradient. Global Biogeochem Cycles. 2010; 24(4). Publisher Full Text 
46. Rapp JM, Silman MR: Diurnal, seasonal, and altitudinal trends in microclimate across a tropical montane cloud forest. Clim Res. 2012; 55(1): 17-32. Publisher Full Text

47. Motzer T, Munz N, Kuppers M, et al.: Stomatal conductance, transpiration and sap flow of tropical montane rain forest trees in the southern Ecuadorian Andes. Tree Physiol. 2005; 25(10): 1283-1293.

PubMed Abstract | Publisher Full Text

48. Cunningham SC: Stomatal sensitivity to vapour pressure deficit of temperate and tropical evergreen rainforest trees of Australia. Trees. 2004; 18(4): 399-407. Publisher Full Text

49. Dial R, Tobin SC: Description of arborist methods for forest canopy access and movement. Selbyana. 1994; 15(2): 24-37.

Reference Source

50. Venables WN, Ripley BD: Modern Applied Statistics with S. 4th ed New York: Springer 2002: 497 Reference Source

51. Bolker BM, Brooks ME, Clark CJ, et al: Generalized linear mixed models: practical guide for ecology and evolution. Trends Ecol Evol. 2009; 24(3): 127-135.

PubMed Abstract | Publisher Full Text

52. R Development Core Team, R: A language and environment for statistical computing. R Foundation for Statistical Computing: Vienna, Austria 2012. Reference Source

53. Oksanen J, Blanchet FG, Kindt R, et al.: Vegan: Community Ecology Package. 2010.

Reference Source

54. Ritter A, Regalado CM, Aschan G: Fog reduces transpiration in tree species of the Canarian relict heath-laurel cloud forest (Garajonay National Park, Spain). Tree Physiol. 2009; 29(4): 517-528.

PubMed Abstract | Publisher Full Text

55. Fierer N, McCain CM, Meir P, et al:: Microbes do not follow the elevational diversity patterns of plants and animals. Ecology. 2011; 92(4): 797-804. PubMed Abstract | Publisher Full Text

56. Jankowski JE, Merkord CL, Rios WF, et al:: The relationship of tropical bird communities to tree species composition and vegetation structure along an Andean elevational gradient. J Biogeogr. 2013; 40(5): 950-962. Publisher Full Text

57. Gentry AH: Patterns of Diversity and Floristic Composition in Neotropical Montane Forests, in Biodiversity and Conservation of Neotropical Montane Forests. SP Churchill, et al., Editors. The New York Botanical Garden: New York. 1995; p.103-126.

Reference Source
58. Gentry $\mathrm{AH}$ : Changes in plant community diversity and floristic composition on environmental and geographical gradients. Ann Mo Bot Gard. 1988; 75: $1-34$. Reference Source

59. Guswa AJ, Rhodes AL, Newell SE: Importance of orographic precipitation to the water resources of Monteverde, Costa Rica. Adv Water Resour. 2007; 30(10): 2098-2112.

Publisher Full Text

60. Häger A, Dohrenbusch A: Hydrometeorology and structure of tropical montane cloud forests under contrasting biophysical conditions in north-western Costa Rica. Hydrol Process. 2011; 25(3): 392-401.

Publisher Full Text

61. Clark KL, Lawton RO, Butler PR: The physical environment, in Monteverde: Conservation and ecology of a tropical cloud forest. NM Nadkarni and NT Wheelwright, Editors. Oxford University Press: New York. 2000; 15-38. Reference Source

62. Marengo JA, Nobre CA, Tomasella J, et al.: The drought of Amazonia in 2005. J Climate. 2008; 21(3): 495-516.

Publisher Full Text

63. Marengo JA, Nobre CA, Tomasella J, et al: Hydro-climate and ecological behaviour of the drought of Amazonia in 2005. Philos Trans R Soc Lond B Biol Sci. 2008 363(1498): 1773-1778.

PubMed Abstract | Publisher Full Text | Free Full Text

64. Zeng N, Yoon JH, Marengo JA, et al:: Causes and impacts of the 2005 Amazon drought. Environ Res Lett. 2008; 3(1): 1-9. Publisher Full Text

65. Stancato GC, Mazzafera P, Buckeridge MS: Effect of a drought period on the mobilisation of non-structural carbohydrates, photosynthetic efficiency and water status in an epiphytic orchid. Plant Physiol Biochem. 2001; 39(11): 1009-1016.

66. Higuera D, Wolf JHD: Vascular epiphytes in dry oak forests show resilience to anthropogenic disturbance, Cordillera Oriental, Colombia. Caldasia. anthropogenic distur 2010; 32(1): $161-174$
Reference Source

67. Saatchi S, Asefi-Najafabady S, Malhi Y, et al:: Persistent effects of a severe drought on Amazonian forest canopy. Proc Natl Acad Sci U S A. 2013; 110(2): 565-570.

PubMed Abstract | Publisher Full Text | Free Full Text

68. Rapp JM, Silman MR: Survey of epiphytes before and after transplantation across an altitudinal gradient of increasing cloud immersion along the eastern slope of the Andes, Peru. figshare, 2013. Data Source 


\section{Open Peer Review}

\section{Current Peer Review Status:}

\section{Version 1}

Reviewer Report 11 March 2014

https://doi.org/10.5256/f1000research.3490.r3105

(C) 2014 Song L. This is an open access peer review report distributed under the terms of the Creative Commons Attribution License, which permits unrestricted use, distribution, and reproduction in any medium, provided the original work is properly cited.

\section{Liang Song \\ Xishuangbanna Tropical Botanical Garden, Chinese Academy of Sciences, Kunming, China}

The purpose of this manuscript is to determine the potential impacts of drought and experimental warming on the performance of vascular epiphytes in a tropical montane cloud forest. There is a lack of information about the effects of climate change on epiphytes in mountain environments. The use of empirical rather than observational data as well as exchanging space for time to demonstrate those effects is also very commendable since such data is extremely rare.

Most studies of the effects of a changing climate on plants in mountain environments focus on changes to the tree line or tree species. However, the choice of epiphytes as experimental subjects in this study is also important, since in my opinion, they would be one of the first groups of organisms to reflect the effects of climate change. Epiphytes have a more direct link to atmospheric conditions and changes to those conditions than plants that root in the soil, and thus are more sensitive to moisture levels as noted by the authors.

This study clearly creates unique data on the impact of climate change on epiphytes and demonstrates an alternative, highly sensitive method of detecting changes in atmospheric conditions in mountain environments. The article is well constructed and clear and the statistical analyses appropriate. Considering that this experiment was conducted in the canopy, the authors must have made a great effort to finish it.

Although the underpinnings of this work are scientifically sound, and some results correlate well with data previously reported for vascular epiphytes by other authors (Nadkarni and Solano, 2002 ), there are several major problems that I feel should be addressed:

1. The time span of the experiment is only one year, which is too short.

2. Microclimatic data was not monitored in the three studied elevations during the experimental period - which may obscure the interpretation of the results.

3. There should be more species with different functional types, which could support the third hypothesis that different functional types (e.g. strap-leaf ferns, orchids, ericaceous shrubs) 
do not respond similarly to moisture gradients. If it is not possible for you to find enough species I would suggest not using 'functional types'.

I have provided a more detailed critique below:

Title:

The title is well chosen although I would suggest adding the location where the study was conducted (e.g. "in the Andes cloud forest"). As noted by the authors, "Cloud forests vary worldwide, with differences in cloud base height and the proportion of moisture received by the vegetation via cloud stripping versus rainfall" and "High rainfall in this part of the Andes may mean that epiphytes here are less dependent on cloud immersion to maintain their water balance than their counterparts in other cloud forests." - This is not a general study concerned about all epiphytes, but a local study restricted to four typical vascular epiphytes in the Andes cloud forest.

\section{Abstract:}

The abstract is basically well written, but the summary of the main findings do not seem appropriate. In the paper, the authors summarize that "Ramet mortality increased, recruitment decreased, and population size declined for epiphytes in mats transplanted down slope from the highest elevation, into warmer and drier conditions", which is not strongly supported by the results. In the results, the authors mention that "Across all species, there were no significant effects on survival of any of the treatments for mats transplanted across elevations (Table 5 and Figure 2). For recruitment and population change, there was a significant interaction between source and transplant elevation (Table 5), with both positively associated with elevation for mats transplanted from 1500 and $1800 \mathrm{~m}$, but negatively associated with altitude for mats from 1650 m (Figure 2)." Different epiphyte species and different parameters showed different response to treatments and sources. The results are much more complicated than what you summarized.

The authors mentioned that their reciprocal transplant design allowed them to distinguish between the effects of moving mats away from their home elevation versus moving plants into lower moisture conditions. As a key control, results concerned about the transplant effect should be included in the abstract.

The authors mention biomass loss in the last sentence, but this conclusion was based on other studies (I guess it is based on Song's results), not their own.

\section{Introduction:}

Paragraph 1: I suggest adding a sentence to illuminate why epiphytes are sensitive to water availability and temperature.

Paragraph 4: The authors mention "Do epiphyte species of different functional types (e.g. strapleaf ferns, orchids, ericaceous shrubs) respond similarly to moisture gradients?" as one of the objectives of the study. If so, why were only four species studied? There is only one fern, one shrub, and two orchids in the experiment. It is not possible, in my opinion, to draw any useful conclusions of functional types with such a limited selection.

Paragraph 5: this paragraph is repeating much of the fourth paragraph, I suggest combining the two. 


\section{Materials and Methods:}

The authors could provide a more detailed description of the four target genera, e.g., "What are the elevational ranges of the target genera in the Andes?" "What is the abundance of the four target genera at different elevations $(1500 \mathrm{~m}, 1650 \mathrm{~m}, 1800 \mathrm{~m})$ ?" etc. This information would be valuable to the interpretation of the results.

Have the authors monitored the microclimatic data of the studied elevations during the experimental period? The details of this data are critical to the interpretation of the results yet it has not been included. Although the July climate for weather stations (Table 1) showed the general pattern of temperature and moisture level along the experimental altitudes it is not the microclimatic data of the study sites, especially as no data was provided at an elevation of $1650 \mathrm{~m}$.

The time span of the experiment is only one year. Longer term monitoring (at least 2 years) at regular intervals (e.g. one year) would be much more valuable. In addition, I would suggest that the authors monitor other physiological parameters such as photosynthesis and chlorophyll fluorescence in their future work. Their conclusions would be much stronger based on these data.

\section{Discussion:}

The title of the paper is "Epiphyte response to drought and experimental warming"; however, the authors do not mention warming in the discussion section. The authors should focus the discussion section more on how different epiphytes respond to drought and warming in this study rather than the reasons for the relative resistance of epiphytes to moisture stress.

The authors overstate their results in some places. For example, they mentioned "Vascular epiphytes transplanted down slope from our highest elevation had lower demographic performance when transplanted to the lowest elevation" in the first sentence of the discussion section. This is only partly true for population change, while not true for survival and recruitment (Fig. 2). Although functional types are mentioned, the authors only have 4 species belonging to 3 functional types.

Paragraph 1: "In general, it appears that epiphytes responded to water stress but we also found evidence for local adaptation." Both temperature and water availability changes along the elevations. Why are you sure that epiphytes responded to water stress not temperature?

Paragraph 2 and 3: Rainfall compensation and drought tolerance seems self-contradictory.

PET: You should provide the full name when it appeared for the first time.

Competing Interests: No competing interests were disclosed.

I confirm that I have read this submission and believe that I have an appropriate level of expertise to confirm that it is of an acceptable scientific standard, however I have significant reservations, as outlined above. 
Author Response 23 May 2014

\section{Joshua Rapp}

We thank Dr. Song for the reviewing our paper and providing constructive feedback. Below we respond to these comments and describe the changes made to the paper in response.

Dr. Song's comments are in [brackets].

1. [The time span of the experiment is only one year, which is too short.]

While we agree that it would have been ideal to extend the study another year, this was not possible due to logistical constraints. Since the experiment was conducted in 2005-2006, it is not possible to add more time to the experiment. We now discuss the effect of experiment duration in the second paragraph of the Discussion.

2. [Microclimatic data was not monitored in the three studied elevations during the experimental period - which may obscure the interpretation of the results.]

We agree that microclimate data during the experiment would have been ideal. Sensors placed at the study site during the experiment stopped recording data soon after deployment. We therefore used data from another period. We added a sentence to the Discussion noting that microclimate data was not available during the period, but refer to rainfall data from the nearby Rocotal climate station.

3. [There should be more species with different functional types, which could support the third hypothesis that different functional types (e.g. strap-leaf ferns, orchids, ericaceous shrubs) do not respond similarly to moisture gradients. If it is not possible for you to find enough species I would suggest not using 'functional types'.]

Since the experimental design focused on plots rather than individual species, we did not have control over the sample size for individual species. In this analysis we used the most abundant species in the plots, to maximize the statistical power to detect differences among treatments. We agree that this experimental design does not allow for a robust test of the hypothesis that functional types may differ in their response to moisture gradients. We therefore removed this hypothesis from the Introduction. However, we include the point in the Discussion, since the experiment does shed some light on differences among functional types, and we feel the Title: patterns are worth mentioning.

[The title is well chosen although I would suggest adding the location where the study was conducted (e.g. "in the Andes cloud forest"). As noted by the authors," Cloud forests vary worldwide, with differences in cloud base height and the proportion of moisture received by the vegetation via cloud stripping versus rainfall" and "High rainfall in this part of the Andes may mean that epiphytes here are less dependent on cloud immersion to maintain their water balance than their counterparts in other cloud forests."

- This is not a general study concerned about all epiphytes, but a local study restricted to four typical vascular epiphytes in the Andes cloud forest.]

Title changed to "Epiphyte response to drought and experimental warming in an Andean cloud forest" 


\section{Abstract:}

[The abstract is basically well written, but the summary of the main findings do not seem appropriate. In the paper, the authors summarize that "Ramet mortality increased, recruitment decreased, and population size declined for epiphytes in mats transplanted down slope from the highest elevation, into warmer and drier conditions", which is not strongly supported by the results. In the results, the authors mention that "Across all species, there were no significant effects on survival of any of the treatments for mats transplanted across elevations (Table 5 and Figure 2). For recruitment and population change, there was a significant interaction between source and transplant elevation (Table 5), with both positively associated with elevation for mats transplanted from 1500 and $1800 \mathrm{~m}$, but negatively associated with altitude for mats from $1650 \mathrm{~m}$ (Figure 2)." Different epiphyte species and different parameters showed different response to treatments and sources. The results are much more complicated than what you summarized.]

We've changed to state that epiphytes moved down slope from the highest elevation had stronger and more negative response than epiphytes moved from other elevations. This also addresses the next comment.

[The authors mentioned that their reciprocal transplant design allowed them to distinguish between the effects of moving mats away from their home elevation versus moving plants into lower moisture conditions. As a key control, results concerned about the transplant effect should be included in the abstract.

The authors mention biomass loss in the last sentence, but this conclusion was based on other studies (I guess it is based on Song's results), not their own.]

We revised the last sentence to focus on how the environmental and evolutionary context may affect epiphyte response to climate change.

\section{Introduction:}

[Paragraph 1: I suggest adding a sentence to illuminate why epiphytes are sensitive to water availability and temperature.]

We added a clause to the sentence: "Cloud immersion is important for many epiphyte species to maintain a positive water balance and avoid desiccation" making it clear that: "this makes them sensitive to changes in moisture regimes." In the next paragraph we describe how cloud formation and temperature are linked, and do not feel that it would add any clarity to the manuscript to repeat that here.

[Paragraph 4: The authors mention "Do epiphyte species of different functional types (e.g. strap-leaf ferns, orchids, ericaceous shrubs) respond similarly to moisture gradients?" as one of the objectives of the study. If so, why were only four species studied? There is only one fern, one shrub, and two orchids in the experiment. It is not possible, in my opinion, to draw any useful conclusions of functional types with such a limited selection.]

We deleted Question (3).

[Paragraph 5: this paragraph is repeating much of the fourth paragraph, I suggest combining the two.]

We deleted the last two sentences referring to functional types. The rest of the paragraph elaborates on the approach outlined in the preceding paragraph. We feel that for clarity it is 
useful to first describe the research questions generally, and then operationalize the general questions. For this reason, we first describe how we expect performance to change with treatments, and then, in the next paragraph, describe the specific performance metrics used, and more specific predictions of how we expected them to change. We have therefore left the structure as is, with one general and one more specific paragraph.

\section{Materials and Methods:}

[The authors could provide a more detailed description of the four target genera, e.g., "What are the elevational ranges of the target genera in the Andes?" "What is the abundance of the four target genera at different elevations $(1500 \mathrm{~m}, 1650 \mathrm{~m}, 1800 \mathrm{~m})$ ?" etc. This information would be valuable to the interpretation of the results.]

All of the genera have broad ranges in Peru, encompassing the study elevations. However, this information is less useful than the elevational distributions of the morpho-species sampled. We have added text in a new section (Focal species) of the Methods to point out more clearly the differences in abundance with elevation of the different target taxa. Table 2 gives the abundance of each the target morpho-species at each elevation.

[Have the authors monitored the microclimatic data of the studied elevations during the experimental period? The details of this data are critical to the interpretation of the results yet it has not been included. Although the July climate for weather stations (Table 1) showed the general pattern of temperature and moisture level along the experimental altitudes it is not the microclimatic data of the study sites, especially as no data was provided at an elevation of $1650 \mathrm{~m}$.]

Unfortunately, temperature and humidity sensors at the study site during the experiment stopped recording data soon after deployment, but this was not discovered until the end of the experiment. Therefore, microclimate data during the experiment is not available. Here we are reporting data for sensors deployed for a different study begun after the experiment that is the focus of this paper. We think this data is still useful, given that it is close to the experimental locations, and better than not reporting any climate data.

[The time span of the experiment is only one year. Longer term monitoring (at least 2 years) at regular intervals (e.g. one year) would be much more valuable. In addition, I would suggest that the authors monitor other physiological parameters such as photosynthesis and chlorophyll fluorescence in their future work. Their conclusions would be much stronger based on these data.]

While we agree that longer term monitoring would be ideal, this was not possible given logistical constraints. Here we are reporting what we did. We have added a sentence to the Discussion ( $2^{\text {nd }}$ paragraph) stating that physiological measurements would be helpful.

\section{Discussion:}

[The title of the paper is "Epiphyte response to drought and experimental warming"; however, the authors do not mention warming in the discussion section. The authors should focus the discussion section more on how different epiphytes respond to drought and warming in this study rather than the reasons for the relative resistance of epiphytes to moisture stress.]

We now mention temperature and moisture together in the first part of the Discussion, since it is not possible from our experimental design to separate the effects of each.

[The authors overstate their results in some places. For example, they mentioned " Vascular epiphytes transplanted down slope from our highest elevation had lower 
demographic performance when transplanted to the lowest elevation" in the first sentence of the discussion section. This is only partly true for population change, while not true for survival and recruitment (Fig. 2). Although functional types are mentioned, the authors only have 4 species belonging to 3 functional types. ]

This is a good point. We have changed the text to place less emphasis on functional types. We still mention differences in functional types as a potential factor in the species-level differences observed, but also include the caveat that our experimental design does not allow the rigorous testing of this hypothesis.

[Paragraph 1: "In general, it appears that epiphytes responded to water stress but we also found evidence for local adaptation." Both temperature and water availability changes along the elevations. Why are you sure that epiphytes responded to water stress not temperature?]

Good point. See above.

[Paragraph 2 and 3: Rainfall compensation and drought tolerance seems selfcontradictory.]

These two effects do act in opposite directions, but both are possible, and non-mutually exclusive. Rainfall compensation could be the usual rule, with occasional drought also providing a selective pressure. We now describe this more clearly at the end of section 1 of the Discussion.

[PET: You should provide the full name when it appeared for the first time.]

Thank you for catching this. Changed to potential evapotranspiration. We also deleted PET, since it only occurs once.

Competing Interests: No competing interests were disclosed.

Reviewer Report 10 March 2014

https://doi.org/10.5256/f1000research.3490.r3588

(C) 2014 Hietz P. This is an open access peer review report distributed under the terms of the Creative Commons Attribution License, which permits unrestricted use, distribution, and reproduction in any medium, provided the original work is properly cited.

\section{Peter Hietz}

Department of Integrative Biology, University of Natural Resources and Applied Life Sciences, Vienna, Austria

This manuscript addresses the question how epiphyte communities in tropical montane forests may be affected by climate change by transplanting epiphyte mats between forests at different altitudes. This is a reasonable proxy of what might happen under climate change with moderate temperature changes and substantial changes in cloud base height and thus available humidity.

The paper is well written, the experiment is clearly described and the analysis is logical (if complex). 
I do suggest some additional thoughts and caveats - for the discussion mainly.

1. As one might expect, the outcome of such a study (four genera, three altitudes, three parameters evaluated) is complex, with significant and (mostly) non-significant effects. Overall the effect was perhaps less than expected (at least compared to a similar study by Nadkarni \& Solano (2009) from Costa Rica). In this case, one tends to pick the significant effects that confirm expectations and ignore those that do not. The authors should avoid simplifying too much, particularly in the abstract, which is what most people will read. The abstract states that "Ramet mortality increased, recruitment decreased, and population size declined for epiphytes in mats transplanted down slope from the highest elevation". This appears to contrast with the results ("Across all species, there were no significant effects on survival of any of the treatments for mats transplanted across elevations").

2. Details of the experimental species used are covered in the methods and results sections, however it seems that the plants were either identified only to the genus level or several species (identified or not) were included within each genus. Unless the authors are sure that only one species per genus was used, they should refer to the groups as "genus", and not "species". It is a substantial difference if we compare one species with individuals adapted to different climates within their phenotypic plasticity, or species differing in their evolutionary adaptations. This should be made clear in the methods section and acknowledged in the discussion.

3. Under drought, plants or ramets may completely die off, but drought first results in weaker plants that exhaust their resources. As such, the effect of being transplanted to a different climate may take more than one year to produce significant effects on population size or also on other parameters studied. This should be acknowledged.

4. The discussion suggests that epiphytes may be fairly drought tolerant in the forest studied because they must have survived unusually dry years (such as 2005, at the beginning of the experiment). This is a good point, and to put this into context it would be good to show precipitation trends (perhaps monthly sums for the closest station available) over several years preceding and including the experiment.

\section{Minor comments:}

Please explain how the daily photographs used to compare the cloud base height were taken and analyzed.

The correct name is Scaphyglottis, not Schaphyglottis.

Why does Table 4 have three elevations for Elaphoglossum, one for Maxillaria (all not significant) and none for the other two genera?"

Competing Interests: No competing interests were disclosed.

I confirm that I have read this submission and believe that I have an appropriate level of expertise to confirm that it is of an acceptable scientific standard. 


\section{Joshua Rapp}

We thank Dr. Hietz for taking time to review our paper and for the constructive comments. These have improved the paper. We respond to these comments below and describe the changes made to the paper in response to these comments. Dr. Hietz' original comments are in [brackets].

1. [As one might expect, the outcome of such a study (four genera, three altitudes, three parameters evaluated) is complex, with significant and (mostly) non-significant effects. Overall the effect was perhaps less than expected (at least compared to a similar study by Nadkarni \& Solano (2009) from Costa Rica). In this case, one tends to pick the significant effects that confirm expectations and ignore those that do not. The authors should avoid simplifying too much, particularly in the abstract, which is what most people will read. The abstract states that "Ramet mortality increased, recruitment decreased, and population size declined for epiphytes in mats transplanted down slope from the highest elevation". This appears to contrast with the results ("Across all species, there were no significant effects on survival of any of the treatments for mats transplanted across elevations"). ]

We have revised the text to be more precise regarding the observed results, especially in the Discussion. In the Abstract we now state that effects were stronger and more negative for epiphytes moved from the highest elevation as compared to those transplanted from other elevations. While this is certainly still a simplification of the results, it does accurately represent the results since significant effects were largely confined to mats transplanted down-slope.

2. [Details of the experimental species used are covered in the methods and results sections, however it seems that the plants were either identified only to the genus level or several species (identified or not) were included within each genus. Unless the authors are sure that only one species per genus was used, they should refer to the groups as "genus", and not "species". It is a substantial difference if we compare one species with individuals adapted to different climates within their phenotypic plasticity, or species differing in their evolutionary adaptations. This should be made clear in the methods section and acknowledged in the discussion. ]

We identified each taxa to morpho-species. This is stated in the first paragraph of the Data collection section of the methods, but was obviously not clear enough. We used species after this point for brevity, but to make it clear to the reader, we have now changed 'species' to 'morpho-species' whenever referring directly to the taxa in the study. We have left 'species' in place where it is used in a more general discussion (i.e. when discussing species composition, species ranges, etc.). We were unable to identify taxa to species definitively because most species were not reproductive during the survey periods. Therefore, while we are fairly certain that our morphospecies were single biological species, it is possible that one or more contain multiple cryptic species. We describe in more detail in the Data collection section why morphospecies were used, and add a sentence acknowledging that taxonomic uncertainty could have affected our results. 
3. [Under drought, plants or ramets may completely die off, but drought first results in weaker plants that exhaust their resources. As such, the effect of being transplanted to a different climate may take more than one year to produce significant effects on population size or also on other parameters studied. This should be acknowledged. ]

Very good point. We added a discussion of this idea to the second paragraph of the Discussion (this is a new paragraph).

4. [The discussion suggests that epiphytes may be fairly drought tolerant in the forest studied because they must have survived unusually dry years (such as 2005 , at the beginning of the experiment). This is a good point, and to put this into context it would be good to show precipitation trends (perhaps monthly sums for the closest station available) over several years preceding and including the experiment.]

Added figure (Figure 4) of monthly rainfall at the closest climate station (Rocotal, 2010m elevation) to the Discussion.

\section{Minor comments:}

[Please explain how the daily photographs used to compare the cloud base height were taken and analyzed.]

Now explained in the Methods.

[The correct name is Scaphyglottis, not Schaphyglottis.]

Thank you. Fixed throughout.

[Why does Table 4 have three elevations for Elaphoglossum, one for Maxillaria (all not significant) and none for the other two genera?"]

Table 2 shows the abundance of each morpho-species in the initial plots at each elevation. For the 'within-species' analysis, we only included source elevations where the morphospecies was abundant (bold in Table 2). Our criteria for "abundant species" is now given in the Methods.

Competing Interests: No competing interests were disclosed. 
The benefits of publishing with F1000Research:

- Your article is published within days, with no editorial bias

- You can publish traditional articles, null/negative results, case reports, data notes and more

- The peer review process is transparent and collaborative

- Your article is indexed in PubMed after passing peer review

- Dedicated customer support at every stage

For pre-submission enquiries, contact research@f1000.com 